\title{
Palinomorfos continentales del Paleógeno de las formaciones Chorrillo Chico y Agua Fresca, Punta Prat, Región de Magallanes, Chile
}

\author{
Rosa Carrillo-Berumen ${ }^{1}$, Mirta E. Quattrocchio ${ }^{2}$, Javier Helenes ${ }^{1}$
}

\author{
${ }^{I}$ CICESE, Departamento de Geología, Km 107 Carretera Tijuana-Ensenada, Baja California, C.P.22860, México. \\ rberumen@cicese.edu.mx; jhelenes@cicese.mx \\ 2 INGEOSUR, Departamento de Geología, San Juan 670, Bahía Blanca, C.P. 8000, Argentina. \\ mquattro@criba.edu.ar
}

\begin{abstract}
RESUMEN. La sección paleógena de Punta Prat, Chile ubicada a 53¹0'S-71²0’W en el sur de la cuenca de MagallanesAustral, incluye las formaciones Chorrillo Chico y Agua Fresca. Ambas unidades contienen una asociación palinológica integrada por palinomorfos marinos y continentales que sugieren un ambiente de depositación marino con aporte de terrígenos. Los taxa continentales encontrados en las formaciones estudiadas reflejan un bosque desarrollado bajo un clima húmedo cálido a templado, dominado por Podocarpaceae, Proteaceae y Nothofagaceae acompañadas de abundantes helechos de las familias Schizaeaceae, Polypodiaceae y Dicksoniaceae. La relación de palinomorfos marinos/ continentales indica una transgresión marina del Paleoceno al Eoceno Medio. Esta transgresión provocó la disminución de humedales hacia la parte superior de la columna, como lo muestra el bajo índice de palinomorfos paludales en la parte alta de la Formación Agua Fresca.
\end{abstract}

Palabras clave: Chorrillo Chico, Agua Fresca, Punta Prat, Paleógeno, Paleoecología, Palinomorfos, Magallanes-Austral, Chile.

\begin{abstract}
Paleogene continental Palynomorphs of the formations Chorrillo Chico and Agua Fresca, Punta Prat, Magallanes, Chile. The Paleogene section of Punta Prat, Chile is located at $53^{\circ} 10^{\prime}$ S $-71^{\circ} 20^{\prime} \mathrm{W}$ in southern Magallanes-Austral Basin, includes Chorrillo Chico and Agua Fresca Formations. Both units contain a palynological assemblage composed of marine and continental palynomorphs indicative of a marine depositional environment with terrigenous input. The continental taxa found in the studied formations reflect a forest developed under a humid warm to temperate climate, dominated by Podocarpaceae, Proteaceae and Nothofagaceae accompanied by abundant ferns belonging to the Schizaeaceae, Polypodiaceae and Dicksoniaceae families. The relationship of marine/continental palynomorphs indicates a marine transgression from the Paleocene to the Middle Eocene. This transgression caused the decline of wetlands towards the top of the column, as shown by the low rate of swamp inhabiting palynomorphs in the upper levels of the Agua Fresca Formation.
\end{abstract}




\section{Introducción}

La cuenca de Magallanes-Austral (Chile-Argentina), desarrollada en el extremo sur de Sudamérica, se relaciona con la evolución de cuencas marinas cenozoicas asociadas al margen tectónicamente activo de los Andes. En la región occidental de la cuenca de Magallanes-Austral, se localiza el afloramiento marino de mayor espesor (aproximadamente $3.000 \mathrm{~m}$ estratigráficos es la suma de espesores de las formaciones Chorrillo Chico y Agua Fresca en sus localidades tipo, en Martínez-Pardo, 1971; Decat y Pomeyrol, 1931) del Paleógeno registrado hasta el momento (Quattrocchio y Sarjeant, 2003), depositado durante el evento regresivo-transgresivo ocurrido del Paleoceno al Eoceno (Malumián, 1999). Este evento solo se había reconocido en los principales depocentros, con base en el estudio de foraminíferos planctónicos y bentónicos (Natland et al., 1974) y de quistes de dinoflagelados (Quattrocchio, 2009), y se encuentra bien representado en la localidad Punta Prat en Chile (Quattrocchio y Sarjeant, 2003).

En este trabajo se documentan por primera vez las asociaciones de palinomorfos continentales de las formaciones Chorrillo Chico y Agua Fresca, Punta Prat (Chile). Esta nueva base de datos complementa la información para caracterizar las condiciones paleoambientales y paleoclimáticas durante el Paleógeno en la Patagonia chilena. Además, estas asociaciones palinológicas se comparan con otras reconocidas en la región austral de América del Sur.

\subsection{Marco Geológico}

La historia tectónica de la cuenca se asocia con la fragmentación de Gondwana durante el TriásicoJurásico, y está relacionada con un régimen tectónico de extensión y el desarrollo de sistemas de ruptura continental (Mpodozis y Ramos, 2008). Representa la apertura inicial de un mar marginal detrás del arco magmático andino a fines del Jurásico y principios del Cretácico (Dalziel et al., 1974; Ghiglione et al., 2002). La deformación compresiva en la parte sur de los Andes produjo el cierre del mar marginal en el Cretácico Tardío (Halpern y Rex, 1972; Olivero y Martinioni, 1996), lo cual provocó una subsidencia mecánica por carga tectónica, que dio origen a la cuenca de Magallanes-Austral (Ghiglione et al., 2002). La evolución de la cuenca durante el Cenozoico es la de una cuenca de antepaís, desarrollada durante la orogenia Andina (Quattrocchio, 2009). El avance de la deformación condicionó una migración sistemática de los depocentros durante el Paleógeno (Olivero y Malumián, 1999; Ghiglione et al., 2002).

En el extremo austral de Sudamérica se acumularon amplios depósitos sedimentarios correspondientes a varias transgresiones del Atlántico: la primera y más extensa ocurrió durante el Maastrichtiano perdurando hasta el Daniano y fue el origen de la Plataforma Patagónica; en el Eoceno Medio Tardío, Oligoceno Tardío-Mioceno Temprano, y el Mioceno Medio (Malumián y Náñez, 2011). Estas alternaron con períodos de depositación no marina y de erosión (Quattrocchio y Sarjeant, 2003; Marenssi et al., 2003). Las transgresiones permitieron la extensión de mares poco profundos, principalmente al oeste de la Plataforma Patagónica, generando con ello condiciones paleoecológicas propias del área (Malumián y Náñez, 2011).

\subsection{Estratigrafía del Paleógeno en Punta Prat}

La localidad Punta Prat está ubicada al oeste de la Península de Brunswick a 53 ${ }^{\circ} 10^{\prime} \mathrm{S}-71^{\circ} 20^{\prime} \mathrm{W}$ en la región Punta Arenas, al sur de Chile. En esta área, las formaciones Chorrillo Chico y Agua Fresca afloran en una plataforma casi horizontal, creada por abrasión marina y expuesta en marea baja (Quattrocchio, 2009). Los tipos de rocas, límites de secuencias y sistemas sedimentarios de la sucesión estudiada fueron tratados por Quattrocchio y Sarjeant (2003). El espesor de la secuencia estratigráfica es de $225 \mathrm{~m}$ de areniscas, limolitas, lutitas y concreciones de caliza, de los cuales los primeros 84 $\mathrm{m}$ corresponden a la Formación Chorrillo Chico y los restantes $141 \mathrm{~m}$ a la Formación Agua Fresca.

El intervalo estratigráfico analizado en el borde de la frontera Argentina-Chile, se ha interpretado como depósitos sedimentarios progradantes de facies de abanicos deltaicos del Paleoceno (Formación Chorrillo Chico y Estratos de Cabo Nariz) (Sánchez et al., 2010), representando un sistema progradante hasta el Eoceno (Formación Agua Fresca) (Prieto y Moraga, 1990). Al noroeste del área de estudio, en la zona de Cabo Nariz (Estratos de Cabo Nariz), predominan facies proximales de abanicos submarinos. Mientras que en la isla Riesco y en la península de Brunswick, donde se ubica la localidad de Punta Prat, predominan las facies distales de los abanicos (Formación Chorrillo Chico) (Sánchez et al., 2010). 


\subsubsection{Formación Chorrillo Chico}

La unidad de roca paleógena más antigua reconocida dentro de esta área es la Formación Chorrillo Chico (Quattrocchio y Sarjeant, 2003), la cual fue nombrada y caracterizada por Thomas (1949). Esta unidad está compuesta principalmente por lutitas, areniscas glauconíticas con concreciones y delgadas capas de caliza (Otero et al., 2012). Los foraminíferos reportados de esta formación indican una edad paleocena sin diferenciar (Martínez-Pardo, 1971). Mientras que la asociación de dinoflagelados permite limitar la edad de esta unidad de Daniano tardío a Selandiano tardío (Quattrocchio y Sarjeant, 2003). La Formación Chorrillo Chico se correlaciona cronoestratigraficamente con los Estratos de Cabo Nariz (Sánchez et al., 2010).

Los quistes de dinoflagelados de la Formación Chorrillo Chico son: Deflandrea boloniensis, Deflandrea cygniformis, Eisenackia crassitabulata, Palaeocystodinium golzowense, Palaeoperidinium pyrophorum, Pyxidinopsis crassimurata, y Spinidinium macmurdoense, pertenecientes al Paleoceno (Quattrocchio, 2009).

En Punta Prat, no se encontró el género de dinoquiste Apectodinum, el que caracteriza el límite Paleoceno-Eoceno en latitudes altas del Hemisferio sur (Quattrocchio, 2009). Esta ausencia sugiere la existencia de una discontinuidad estratigráfica (hiato-laguna) en el techo de la Formación Chorrillo Chico, la que ya ha sido interpretada como de carácter regional (Biddle et al., 1986). Aparentemente, esta discontinuidad es común en la Patagonia y en el subsuelo de las cuencas Magallanes-Austral y Malvinas-Falklands.

\subsubsection{Formación Agua Fresca}

La Formación Agua Fresca fue establecida por Decat y Pomeyrol (1931) y su localidad tipo aflora a lo largo del río Agua Fresca (sur de Chile). Está compuesta por lutitas grises con algunas concreciones de caliza. Esta Formación ha sido asignada al Eoceno Temprano a Medio sobre la base de la asociación de quistes de dinoflagelados, entre los cuales los más significativos son: Achilleodinium biformoides, Achilleodinium latispinosum, Alterbidinium distinctum, Deflandrea antarctica, Impagidinium cassiculum, Lejeunecysta fallax, Pyxidiniopsis delicata, Spinidinium asymmetricum y Volkheimeridium lanterna (Quattrocchio, 2009).

Los afloramientos que corresponden a la Formación Agua Fresca aparentemente son en parte correlacio- nables con la Formación Punta Torcida, que aflora en el norte de Tierra del Fuego (Malumián, 1999; Malumián y Náñez, 2011), a la que se ha asignado una edad entre Ypresiano (Olivero y Malumián, 2008) y Luteciano Temprano (ca. 47,3 Ma) sobre la base de circones detríticos para sus términos más jóvenes (Barbeau et al., 2009). La base no está expuesta y el techo corresponde a una discordancia angular por debajo de estratos del Luteciano superior. Algunos investigadores consideran que la Formación Punta Torcida representa una acumulación en posición distal al depocentro para esa edad (Torres-Carbonell, 2010).

\section{Metodología}

\subsection{Procesamiento y análisis palinológico}

Fueron procesadas para análisis palinológico 21 muestras de las formaciones Chorrillo Chico (9) y Agua Fresca (12). Se prepararon con el procedimiento estándar de digestión con ácidos para estudios palinológicos en el Laboratorio de Palinología de la Universidad de Saskatchewan, Canadá. Las 21 muestras estudiadas forman parte de las colecciones del Laboratorio de Palinología del Departamento de Geología de la Universidad Nacional del Sur, Bahía Blanca, Argentina, y están registradas con las siglas UNSP (Punta Prat), seguidas del número de muestra de laboratorio (num.) acompañadas de letras minúsculas $(\mathrm{a}, \mathrm{b}$, etc.) que representan los distintos preparados. En todas ellas se encontraron palinomorfos, los que fueron identificados cuando menos como género, aunque en la mayoría de los casos se logró la identificación como especie. El análisis microscópico se realizó con un microscopio Olympus BH-2 y se obtuvieron imágenes de los especímenes mejor preservados, mediante una cámara digital Olympus Camedia C-5060.

\subsection{Análisis cuantitativo}

Se realizó un análisis cuantitativo de las 21 muestras, considerando la suma total de especímenes en ellas. Para cada muestra, se reporta el conteo total de especímenes de palinomorfos continentales (esporas, granos de polen de gimnospermas y angiospermas) y marinos (dinoflagelados, acritarcas, moldes de microforaminíferos y escolecodontes) observados y se grafican los datos tanto en porcentajes como en conteos totales y se incluye la riqueza de especies 
con la finalidad de observar e interpretar cambios verticales del conjunto de palinomorfos.

\section{3. Índice de Shannon}

El Índice de Diversidad de Shannon, mide la diversidad de cada muestra, la que se puede definir como probabilidad de seleccionar cada una de las especies en la proporción con que existen en las muestras (Shannon y Weaver, 1949), usando la siguiente fórmula:

$$
\mathrm{H}^{\prime}=-\sum_{i=1}^{k} p i \ln p i
$$

Donde $k$ es el número de especies presentes (riqueza de especies), pi es la proporción de individuos de la especie $i$ respecto al total de individuos (es decir, la abundancia relativa de la especie $i$ ).

\subsection{Prueba de Hutcheson}

Para validar los valores de diversidad obtenidos se realizaron pruebas de Hutcheson (t de student), mediante las cuales se determina la posible existencia de diferencias significativas entre los valores de los Î́ndices de Diversidad de Shannon (Zar, 1999).

\section{5. Índice de Palinomorfos Marinos (IPM)}

Los datos de las riquezas de palinomorfos marinos y continentales fueron utilizados para calcular el Índice Palinológico Marino (IPM) modificado de Helenes et al. (1998), que es la razón entre la riqueza (número de especies) de palinomorfos marinos sobre la de palinomorfos continentales. El valor del IPM es directamente proporcional a la riqueza de palinomorfos marinos e inversamente proporcional a la riqueza de los palinomorfos continentales, su expresión es la siguiente:

$$
\mathrm{IPM}=\frac{R m}{(R m+R c)} * 100
$$

Donde $R m$ es la riqueza de palinomorfos marinos y $R c$ es la riqueza de palinomorfos continentales. Los valores altos del IPM indican un ambiente marino, mientras que los valores bajos indican la influencia de aguas salobres, ambientes paludales costeros, estuarinos o deltaicos. Los valores nulos representan ambientes exclusivamente continentales.

\section{6. Índice de Paludales (IPAL)}

En esta contribución se propone realizar el calculo del Índice de Paludales (IPAL), utilizando la razón entre los datos de la riqueza del conjunto de los palinomorfos asociados con ambientes de tierras bajas y con poco drenaje, denominado palinomorfos paludales, sobre la riqueza de palinomorfos paludales más la riqueza de palinomorfos marinos, por lo tanto, el valor del IPAL es directamente proporcional a la riqueza de palinomorfos paludales e inversamente proporcional a la riqueza de los palinomorfos marinos, su expresión es la siguiente:

$$
\mathrm{IPAL}=\frac{\text { Rpal }}{(\text { Rpal }+R m)} * 100
$$

Donde $R$ pal es la riqueza de palinomorfos palustres y $R m$ es la riqueza de palinomorfos marinos. Los valores altos del IPAL indican un ambiente paludal, mientras que los valores bajos indican la influencia de agua de mar. Los valores nulos representan ambientes exclusivamente marinos.

\subsection{Coeficiente de Similitud de Jaccard}

La asociación de palinomorfos continentales de las formaciones Chorrillo Chico y Agua Fresca fue comparada con las provenientes de diversas formaciones y/o localidades paleógenas de Sudamérica. Esta comparación estadística se realizó mediante el análisis de agrupamientos (clusters), valores del Índice de Diversidad de Shannon y el Coeficiente de Similitud de Jaccard (SJ) para datos binarios. Este último se obtuvo mediante la ecuación siguiente: $\mathrm{SJ}=\mathrm{a} / \mathrm{a}+\mathrm{b}+\mathrm{c}$ utilizando el programa Paleontological Statistics PAST (Hammer et al., 2001).

\section{Resultados}

\subsection{Estadística de Palinomorfos en Punta Prat}

Las muestras contienen una abundante asociación de palinomorfos bien preservados y en la totalidad de ellas existe un ligero dominio de palinomorfos 
marinos (58\%). En general, los palinomorfos continentales $(42 \%)$ están representados por esporas de Bryophytas y Pteridophytas (55\%), granos de polen de gimnospermas (31\%) y granos de polen de angiospermas (14\%); la tabla 1 incluye los conteos de los taxa continentales identificados por muestra de las formaciones Chorrillo Chico y Agua Fresca.

Los conteos totales de especímenes de palinomorfos (marinos y continentales) por muestra alcanzan un máximo de 749 (muestra PP-11), un mínimo de 288 (muestra PP-18) y un promedio en la totalidad de las muestras de 490 especímenes (Fig. 1).

La riqueza de especies está representada en un 57\% por palinomorfos marinos y $43 \%$ por continentales. La riqueza total de taxa (marinos y continentales) varía desde 70 (muestra PP-11) a 35 (muestra PP-18). Los valores más altos del Índice de Diversidad de Shannon se presentan en la Formación Chorrillo Chico (2.1) y los más bajos (1.3) en la base de la Formación Agua Fresca que corresponde al Eoceno Temprano (Fig. 1). No se encontraron diferencias significativa entre los índices de diversidad ( $p>0.42$ ).

\subsubsection{Grupos continentales presentes en Punta Prat}

La tabla 2 incluye todos los taxa identificados durante el presente estudio y las familias a los que se asocian. Los siguientes son los grupos importantes en este estudio.

Esporas. El grupo de palinomorfos continentales más abundante con un $55 \%$ (el 28\% corresponde a la Formación Chorrillo Chico y el 27\% a la Formación Agua Fresca) es el de las esporas de Bryophytas y Pteridophytas; considerando el $100 \%$ de las esporas, el $35 \%$ (15 y 20\%, el primer dato corresponde a la parte proporcional de la Formación Chorrillo Chico y el segundo dato a la de la Formación Agua Fresca) de ellas pertenecen a la familia Schizaeaceae, el 23\% (14 y 9\%) a la familia Polypodiaceae y el 15\% (9 y $6 \%$ ) a la familia Dicksoniaceae, el $27 \%$ (13 y 14\%) restante pertenece a otras familias de helechos. Del total de esporas, los géneros observados con mayor frecuencia son: Biretisporites con un 24\% (11 y 13\%), Deltoidospora con un 22\% (13 y 9\%), Klukisporites con un $11 \%$ (4 y 7\%), Trilites con un $8 \%$ (5 y $3 \%$ ) y el $35 \%(17$ y $18 \%)$ restante pertenece a otras esporas de menor frecuencia.

Gimnospermas. El grupo de las gimnospermas está representado por granos de polen bi- $\mathrm{y}$ tri-sacados e inaperturados. Del total de las gimnospermas (consideradas como el 100\%) observadas, las po- docarpáceas representan el 97\% (34 y 63\%) y las araucariáceas el 3\% (1 y 2\%). El género Podocarpidites representa el $80 \%$ de las podocarpáceas en Punta Prat y solo el 7,5\% corresponde a la especie bisacada Phyllocladidites mawsonii.

Angiospermas. De la totalidad de las angiospermas, el 58\% (23 y 35\%, el primer dato corresponde a la parte proporcional de la Formación Chorrillo Chico y el segundo a la de la Formación Agua Fresca) pertenece a la familia Proteaceae. La especie más abundante de esta familia es Peninsulapollis gillii (Cretácico Tardío al Eoceno) y se encuentra a lo largo de toda la columna.

La familia Nothofagaceae (Nothofagidites) constituye el 35\% (29 y 6\%) de las angiospermas. El 81\% (170) del conteo total de Nothofagidites (209) se concentran en la Formación Chorrillo Chico (Paleoceno), donde el 43\% corresponde a los tipo brassii y el resto a los tipo fusca y menziesii (57\%). En la Formación Agua Fresca (Eoceno Temprano a Medio) se encuentra el 19\% (39) restante del total de los conteos de Nothofagidites, donde el 41\% (16) corresponde al tipo brassii y el 59\% (23) a los tipo fusca y menziesii. En general, el comportamiento lineal de Nothofagidites es descendente hacia los niveles superiores de la columna, lo que indica una disminución en los conteos de nothofagáceas en Punta Prat del Paleoceno al Eoceno Medio (Fig. 2).

Taxa paludales. Las esporas de Deltoidospora se han relacionado con helechos de polipodiáceas del Eoceno al Oligoceno (Traverse, 1994) y han sido consideradas afines al género paludal Acrostichum (Collinson, 1978). En esporas dispersas en los sedimentos y en pinnas fértiles de Acrostichum palaeoaureum (García-Massini et al., 2006), se observa que la densidad y el tamaño de los gránulos en la cara proximal de las esporas varían mucho, encontrando especímenes casi psilados y otros con una gran abundancia de gránulos (J.L. García-Massini, comunicación personal, 2012). La variedad aquí observada de esporas psiladas (D. australis y D. minor) y con gránulos (Deltoidospora sp.) permite sugerir una afinidad con el género paludal Acrostichum.

En la base de la Formación Chorrillo Chico (PP-5 a la PP-11) durante el Paleoceno, se observa la presencia de la especie Pandaniidites texus que se asocia con el género actual de ambiente tropical costero o paludal Pandanus (Narváez, 2009). El género Pandaniidites junto con: Phyllocladidites mawsonii, Spinozonocolpites (asociado actualmente a Nypa), Nothofagidites tipo 
TABLA 1. CONTEOS DE TAXA DE PALINOMORFOS CONTINENTALES POR MUESTRA EN LAS FORMACIONES CHORRILLO CHICO Y AGUA FRESCA.

\begin{tabular}{|c|c|c|c|c|c|c|c|c|c|c|c|c|c|c|c|c|c|c|c|c|c|c|}
\hline \multirow{2}{*}{\multicolumn{2}{|c|}{\begin{tabular}{|r|} 
FORMACIÓN \\
TAXA / MUESTRA
\end{tabular}}} & \multicolumn{8}{|c|}{ CHORRILLO CHICO } & \multicolumn{13}{|c|}{ AGUA FRESCA } \\
\hline & & $\mathfrak{n}^{n}$ & ì & $\hat{a}$ & $\begin{array}{l}\infty \\
\stackrel{1}{a} \\
\stackrel{1}{a}\end{array}$ & $\hat{a}$ & $\frac{9}{a}$ & $\overline{\bar{a}}$ & $\frac{1}{1}$ & $\frac{m}{1}$ & $\frac{ \pm}{a}$ & $\frac{a}{a}$ & $\frac{5}{a}$ & $\frac{\infty}{a}$ & $\begin{array}{l}\text { 彳ิ } \\
\hat{a}\end{array}$ & $\stackrel{\bar{a}}{a}$ & $\stackrel{\tilde{I}}{\grave{a}}$ & $\stackrel{\tilde{1}}{\hat{a}}$ & 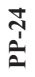 & $\stackrel{\stackrel{2}{1}}{\stackrel{1}{a}}$ & $\begin{array}{c}\stackrel{1}{1} \\
\stackrel{1}{a}\end{array}$ & กิ \\
\hline \multirow{30}{*}{ 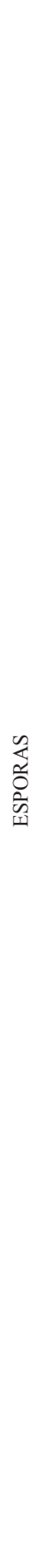 } & $\begin{array}{l}\text { Baculatisporites } \\
\text { comaumensis }\end{array}$ & 5 & 3 & - & - & 1 & 3 & 15 & 7 & - & 2 & 4 & - & - & 1 & 1 & 3 & - & - & 10 & 12 & 9 \\
\hline & Baculatisporites sp. & - & - & - & - & - & - & - & - & - & - & - & - & - & - & - & - & 1 & - & - & - & - \\
\hline & $\begin{array}{l}\text { Baculatisporites } \\
\text { turbioensis }\end{array}$ & - & - & - & - & 1 & 4 & 4 & 2 & - & 1 & 1 & - & - & - & - & - & - & - & 1 & - & - \\
\hline & $\begin{array}{l}\text { Biretisporites } \\
\text { crassilabratus }\end{array}$ & - & - & - & - & - & - & - & 3 & - & 4 & 2 & - & 5 & 16 & 3 & - & 25 & 13 & 8 & 3 & 6 \\
\hline & Biretisporites sp. & 24 & 61 & 27 & 21 & 47 & 30 & 25 & 20 & 37 & 18 & 9 & 5 & 13 & 6 & 1 & 7 & 7 & 30 & 26 & 39 & 18 \\
\hline & Ceratosporites equalis & 1 & - & 1 & - & - & 1 & - & 2 & 19 & - & - & - & - & - & - & 2 & - & - & - & - & - \\
\hline & Cingutriletes australis & 5 & 10 & 2 & 4 & - & 26 & 18 & - & - & 6 & 8 & 5 & 1 & 8 & 2 & 1 & 3 & - & - & 9 & - \\
\hline & Clavifera triplex & - & - & - & - & - & 1 & - & - & - & - & - & - & - & - & - & - & - & - & - & - & - \\
\hline & Cyatheacidites annulatus & - & 1 & 2 & - & 3 & 2 & 7 & - & 11 & 1 & - & - & - & 2 & - & - & 7 & - & 6 & 5 & 2 \\
\hline & Deltoidospora australis & 6 & 22 & 26 & 12 & 19 & 12 & 22 & 4 & 6 & 5 & 5 & 18 & 4 & 10 & 3 & - & 4 & 5 & 16 & 3 & 3 \\
\hline & Deltoidospora minor & 7 & 25 & 8 & 17 & 21 & 19 & 32 & 3 & 5 & 9 & 6 & 11 & - & 11 & - & - & - & 16 & 19 & 10 & 3 \\
\hline & Deltoidospora $\mathrm{sp}$. & 12 & 28 & 4 & 12 & 3 & 3 & 2 & - & 15 & 7 & - & - & - & 4 & 3 & 1 & - & - & - & - & - \\
\hline & Dictyophyllidites harrisii & 7 & - & - & - & 11 & 3 & - & - & 18 & 2 & - & - & - & 2 & - & 1 & - & 2 & - & - & 4 \\
\hline & Dictyophyllidites sp. & - & 2 & - & - & - & - & - & - & - & - & - & - & - & - & - & - & - & - & - & - & - \\
\hline & Gleicheniidites senonicus & 8 & 13 & 6 & 8 & - & 15 & 20 & 1 & - & 3 & 4 & 3 & 1 & 2 & 1 & - & - & - & 13 & 4 & 4 \\
\hline & Gleicheniidites sp. & 2 & 2 & - & 2 & - & 5 & - & 2 & - & 1 & - & 19 & - & 1 & 3 & - & - & - & - & - & - \\
\hline & $\begin{array}{l}\text { Ischyosporites } \\
\text { areapunctatis }\end{array}$ & 4 & 7 & 3 & - & 5 & 4 & 4 & - & 6 & 2 & 4 & - & - & - & - & - & - & - & - & 7 & - \\
\hline & Ischyosporites sp. & 10 & 11 & 2 & 3 & 1 & 6 & 7 & 3 & 2 & 6 & 3 & - & - & - & - & 3 & 3 & 3 & - & 4 & 2 \\
\hline & Klukisporites labiatus & - & - & - & - & - & - & - & - & - & 2 & 13 & - & - & - & - & - & - & - & - & - & - \\
\hline & $\begin{array}{l}\text { Klukisporites } \\
\text { pseudoreticulatus }\end{array}$ & - & - & - & - & 3 & - & - & - & - & 4 & 7 & - & - & 4 & 2 & - & - & - & - & 4 & - \\
\hline & Klukisporites sp. & 12 & 4 & 11 & 10 & 14 & 20 & 15 & 5 & 16 & 8 & - & 7 & 6 & 8 & 3 & 9 & 15 & 3 & 18 & 20 & 26 \\
\hline & Klukisporites variegatus & 5 & - & - & 1 & 1 & 6 & - & - & - & - & - & - & - & - & - & - & - & - & - & - & - \\
\hline & Laevigatosporites ovatus & 10 & 7 & 5 & 2 & 3 & 16 & 7 & - & - & 3 & 2 & 3 & 2 & 16 & 4 & 3 & 11 & 4 & 6 & 6 & 7 \\
\hline & Matonisporites sp. & 2 & - & - & - & - & 1 & - & - & - & - & - & - & - & 2 & - & - & - & - & - & - & - \\
\hline & Peromonolites vellosus & - & - & - & 4 & - & - & - & - & - & - & - & - & - & - & - & - & - & - & - & 2 & 3 \\
\hline & $\begin{array}{l}\text { Polypodiisporites } \\
\text { inangahuensis }\end{array}$ & - & 1 & - & - & - & - & - & - & - & - & - & - & - & - & - & - & - & - & - & - & - \\
\hline & $\begin{array}{l}\text { Retitriletes } \\
\text { austroclavatidites }\end{array}$ & 7 & 2 & 2 & 4 & - & 6 & 5 & 3 & - & 5 & 2 & 8 & - & 18 & 3 & 4 & 19 & 6 & 3 & 3 & 2 \\
\hline & Retitriletes sp. & 2 & - & - & - & - & - & - & - & - & - & - & - & - & - & - & - & - & - & - & - & - \\
\hline & Trilites sp. & 18 & 22 & 8 & 15 & 6 & 25 & 10 & 13 & 15 & 5 & 5 & 11 & 1 & 12 & 5 & - & 15 & - & - & - & - \\
\hline & Verrucatosporites sp. & - & 2 & - & - & - & - & - & - & - & - & - & - & - & - & - & - & - & - & - & - & - \\
\hline
\end{tabular}


continuación tabla 1.

\begin{tabular}{|c|c|c|c|c|c|c|c|c|c|c|c|c|c|c|c|c|c|c|c|c|c|c|}
\hline \multirow{2}{*}{\multicolumn{2}{|c|}{\begin{tabular}{|c|} 
FORMACIÓN \\
TAXA / MUESTRA
\end{tabular}}} & \multicolumn{8}{|c|}{ CHORRILLO CHICO } & \multicolumn{13}{|c|}{ AGUA FRESCA } \\
\hline & & $\mathfrak{a}^{n}$ & $\stackrel{1}{1}^{1}$ & $\hat{a}$ & $\begin{array}{l}\infty \\
\hat{a} \\
\hat{a}\end{array}$ & $\frac{\hat{a}}{a}$ & $\frac{0}{a}$ & $\bar{z}$ & $\frac{1}{a}$ & $\frac{m}{a}$ & $\frac{\Delta}{a}$ & $\frac{0}{a}$ & $\frac{1}{2}$ & $\frac{\infty}{a}$ & 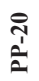 & $\overline{\hat{I}}$ & $\underset{\mathfrak{I}}{\stackrel{I}{a}}$ & $\underset{i}{\tilde{a}}$ & $\frac{\vec{a}}{a}$ & $\stackrel{n}{a}$ & 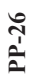 & $\frac{\widehat{N}}{a}$ \\
\hline \multirow{14}{*}{ 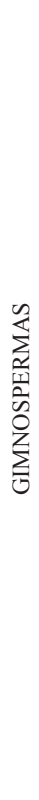 } & Araucariacites australis & - & - & - & - & - & - & - & - & - & 2 & 3 & 4 & 3 & 1 & 2 & - & - & 1 & - & - & - \\
\hline & $\begin{array}{l}\text { Araucariacites } \\
\text { pergranulatus }\end{array}$ & 1 & - & - & - & - & - & - & - & - & - & - & - & - & - & - & - & - & - & - & - & - \\
\hline & Araucariacites sp. & 7 & 2 & - & 2 & 1 & 2 & 3 & - & - & - & - & - & - & - & - & - & - & 3 & - & 3 & - \\
\hline & $\begin{array}{l}\text { Dacrycarpites } \\
\text { australiensis }\end{array}$ & - & - & 3 & - & - & - & 7 & 2 & - & 3 & 1 & 5 & - & 13 & 8 & - & 6 & - & - & 4 & 4 \\
\hline & Gamerroites psilasaccus & 2 & - & 2 & 1 & - & - & 2 & - & - & 1 & 1 & 4 & - & 4 & 2 & - & 12 & 12 & - & 2 & - \\
\hline & Gamerroites sp. & 2 & - & - & - & - & - & - & - & - & - & - & - & - & - & - & - & - & - & - & - & - \\
\hline & $\begin{array}{l}\text { Microcachrydites } \\
\text { antarcticus }\end{array}$ & - & - & 1 & 3 & - & 9 & 1 & 2 & 3 & - & 5 & - & - & 14 & 14 & - & 8 & - & - & 3 & - \\
\hline & Phyllocladidites mawsonii & 3 & 1 & 2 & 17 & 3 & 3 & 4 & 2 & - & 3 & 4 & - & 1 & 7 & - & - & - & - & 3 & 31 & 12 \\
\hline & Podocarpidites elegans & 2 & - & 8 & 3 & - & 9 & 14 & 10 & 2 & 2 & - & - & - & 7 & - & 1 & 11 & - & - & 15 & - \\
\hline & Podocarpidites ellipticus & - & - & - & - & 3 & - & - & - & - & 5 & 3 & 11 & 5 & - & 11 & 3 & - & 5 & - & 15 & - \\
\hline & Podocarpidites marwickii & 19 & 12 & 9 & 2 & 16 & 23 & 14 & 8 & 18 & 18 & 32 & 26 & 12 & 20 & 17 & 18 & 18 & 27 & 23 & 31 & 20 \\
\hline & $\begin{array}{l}\text { Podocarpidites } \\
\text { microreticuloidatus }\end{array}$ & - & 3 & 4 & 8 & - & - & 8 & 3 & 8 & 5 & - & - & 2 & - & - & - & 19 & 8 & 7 & 3 & - \\
\hline & Podocarpidites rugulosus & - & - & - & - & - & - & - & - & - & 1 & - & - & - & 3 & - & - & - & - & - & - & - \\
\hline & Podocarpidites sp. & 20 & 14 & 23 & 20 & 29 & 37 & 38 & 20 & 21 & & 25 & 2 & 23 & 33 & 8 & 10 & 13 & 20 & 10 & 6 & 26 \\
\hline \multirow{19}{*}{ 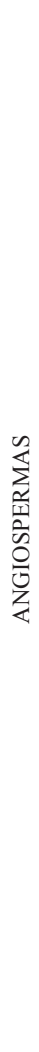 } & Liliacidites sp. & - & - & - & - & - & - & - & 1 & - & 1 & - & - & - & 1 & - & - & - & - & - & - & - \\
\hline & Liliacidites variegatus & 1 & - & - & - & - & - & - & - & - & - & - & - & - & - & - & - & - & - & - & - & - \\
\hline & Margocolporites sp. & - & - & - & - & - & 1 & - & - & - & - & - & - & - & - & - & - & - & - & - & - & - \\
\hline & Monocolpites sp. & - & - & - & - & - & - & - & 1 & - & - & - & - & - & - & - & - & - & - & - & - & - \\
\hline & $\begin{array}{l}\text { Nothofagidites } \\
\text { (tipo brassii) }\end{array}$ & 8 & 15 & 5 & 11 & 8 & 13 & 10 & 3 & 5 & 2 & - & - & - & 1 & - & - & 2 & 1 & - & 3 & 2 \\
\hline & $\begin{array}{l}\text { Nothofagidites } \\
\text { (tipo fusca) }\end{array}$ & 12 & 5 & 2 & 4 & 4 & 7 & 6 & 7 & 3 & - & 3 & 3 & - & 3 & 4 & 2 & 3 & - & 1 & - & - \\
\hline & $\begin{array}{l}\text { Nothofagidites } \\
\text { (tipo menziesii) }\end{array}$ & 3 & 26 & 2 & 4 & 5 & 2 & 2 & 6 & - & - & - & - & - & - & - & 1 & - & - & - & - & - \\
\hline & Pandaniidites texus & 1 & - & - & 3 & 11 & - & - & 3 & - & - & - & - & - & - & - & - & - & - & - & - & - \\
\hline & Peninsulapollis gillii & 10 & 23 & 3 & 8 & 13 & 11 & 12 & 9 & 15 & 4 & 3 & - & 3 & 2 & 12 & - & 20 & 6 & 4 & 8 & 16 \\
\hline & $\begin{array}{l}\text { Propylipollis } \\
\text { pseudomoides }\end{array}$ & 4 & 1 & 8 & 4 & - & - & 5 & - & - & - & 1 & - & - & 3 & - & - & - & - & - & - & - \\
\hline & Propylipollis sp. & 1 & 3 & - & - & - & - & - & - & - & - & - & - & - & - & - & - & - & - & 14 & - & 12 \\
\hline & Proteacidites sp. & - & - & - & - & - & - & - & - & - & - & - & 3 & - & 5 & - & 4 & 4 & 13 & 2 & 15 & 10 \\
\hline & Proteacidites subscabratus & 1 & 8 & - & 7 & - & 3 & 3 & 2 & 13 & 5 & 2 & - & - & - & - & - & - & - & - & 8 & - \\
\hline & Psilatricolporites sp. & - & - & - & - & - & - & - & - & - & - & 1 & - & - & - & - & - & - & - & - & - & - \\
\hline & Rousea sp. & - & - & - & - & - & - & 1 & - & - & - & - & - & 1 & - & - & - & - & - & - & - & - \\
\hline & Spinozonocolpites sp. & 3 & - & - & - & - & - & - & - & - & - & - & - & - & 1 & - & - & - & - & - & - & - \\
\hline & Tetracolpites sp. & - & 1 & - & - & - & - & - & - & - & - & - & - & - & - & - & - & - & - & - & - & - \\
\hline & Tricolpites $\mathrm{sp}$. & - & 1 & - & - & - & - & 1 & - & - & - & - & - & - & - & - & - & - & - & - & 1 & 1 \\
\hline & Triorites minor & - & - & - & - & - & - & - & - & - & - & - & - & - & - & - & - & 1 & - & - & - & - \\
\hline
\end{tabular}




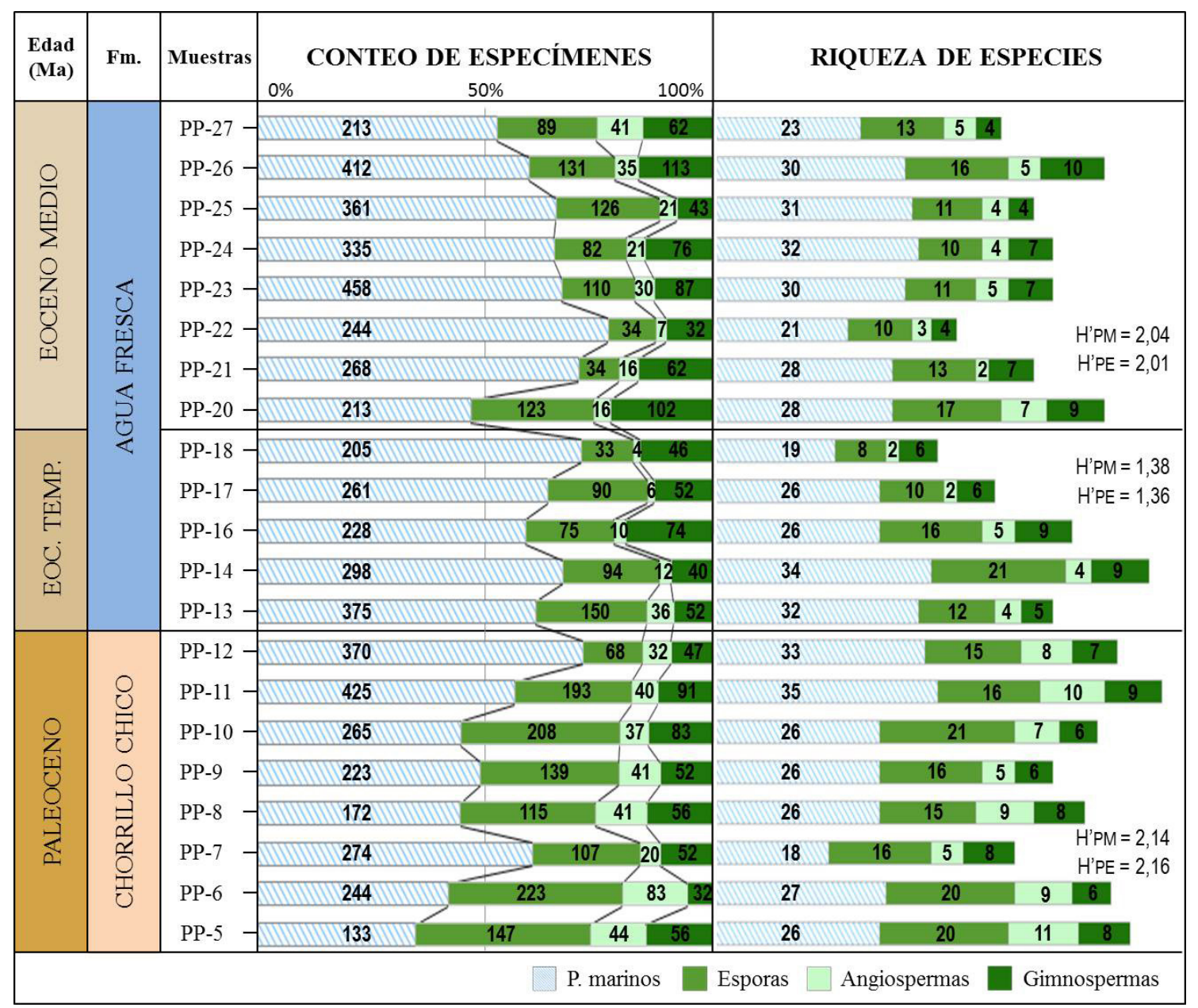

FIG. 1. Estadística de palinomorfos observados en las muestras de Punta Prat. Los conteos de especímenes están representados en porcentajes y conteos totales. La riqueza de especies; con el valor del Índice de Diversidad de Shannon (H'), donde PM representa a los Palinomorfos marinos y PE a los granos de polen y esporas.

brassii (ahora tipo Brassospora Hill y Read, 1991) y Deltoidospora, representan en esta investigación al grupo de palinomorfos paludales, los cuales, a excepción de Pandaniidites texus, se encuentran presentes en las formaciones Chorrillo Chico y Agua Fresca.

\subsection{2. Índices IPM e IPAL}

El Índice de Palinomorfos Marinos (IPM) presenta un comportamiento cíclico con tendencia a aumentar de la Formación Chorrillo Chico hacia la Formación Agua Fresca (Fig. 2). Sin embargo, en la base de esta última unidad, durante el Eoceno Temprano, se observan grandes variaciones en los valores del IPM, con un valor bajo en la muestra PP-16 (46,4), contiguo a uno de los valores más alto de toda la columna (59,1 en la PP-17), y seguido por una disminución de IPM hacia la base del Eoceno Medio. La parte alta de la Formación Agua Fresca presenta un aumento en los valores hasta el tope de la columna donde se observa una disminución.

El Índice de Paludales (IPAL) también muestra un comportamiento cíclico, con tendencia a disminuir del Paleoceno al Eoceno Temprano (Fig. 2). En la parte superior de la columna, en la Formación Agua Fresca (Eoceno Medio), se observan variaciones en los valores del IPAL; en la muestra PP-20 se presenta un valor alto $(21,4)$, seguido de una disminución en los valores hasta 4,8 (PP-22) y nuevamente un ligero incremento hasta la cima de la columna. En forma general, el comportamiento del IPAL es inverso al 
TABLA 2. LISTA DE LOS TAXONES IDENTIFICADOS Y SUS AFINIDADES BOTÁNICAS.

\begin{tabular}{|c|c|c|}
\hline \multicolumn{2}{|r|}{ TAXA } & AFINIDAD BOTÁNICA \\
\hline \multirow{30}{*}{ 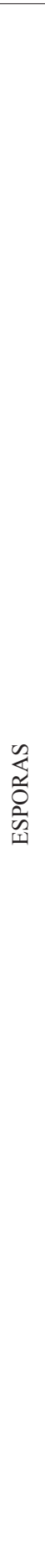 } & Baculatisporites comaumensis (Cookson) Potonie, 1956. & Hymenophyllaceae \\
\hline & Baculatisporites sp. & Hymenophyllaceae \\
\hline & Baculatisporites turbioensis Archangelsky, 1972. & Osmundaceae \\
\hline & Biretisporites crassilabratus Archangelsky, 1972. & Schizaeaceae \\
\hline & Biretisporites sp. & Schizaeaceae \\
\hline & Ceratosporites equalis Cookson y Dettmann, 1958. & Selaginellaceae \\
\hline & Cingutriletes australis (Cookson) Baldoni y Barreda, 1986. & Sphagnaceae \\
\hline & Clavifera triplex (Bolkhovitina) Bolkhovitina, 1966. & Gleicheniaceae \\
\hline & Cyatheacidites annulatus Cookson ex Potonie, 1956. & Cyatheaceae \\
\hline & Deltoidospora australis (Couper) Pocock, 1970. & Polypodiaceae \\
\hline & Deltoidospora minor (Couper) Pocock, 1970. & Polypodiaceae \\
\hline & Deltoidospora sp. & Polypodiaceae \\
\hline & Dictyophyllidites harrisii Couper, 1958. & Matoniaceae \\
\hline & Dictyophyllidites sp. & Matoniaceae \\
\hline & Gleicheniidites senonicus Ross, 1949. & Gleicheniaceae \\
\hline & Gleicheniidites sp. & Gleicheniaceae \\
\hline & Ischyosporites areapunctatis (Stuchlik) Barreda, 1996. & Dicksoniaceae \\
\hline & Ischyosporites $\mathrm{sp}$. & Dicksoniaceae \\
\hline & Klukisporites labiatus (Volkheimer) Baldoni y Archangelsky, 1983. & Schizaeaceae \\
\hline & Klukisporites pseudoreticulatus Couper, 1958. & Schizaeaceae \\
\hline & Klukisporites sp. & Schizaeaceae \\
\hline & Klukisporites variegatus Couper, 1958. & Schizaeaceae \\
\hline & Laevigatosporites ovatus Wilson y Webster, 1946. & Bleichnaceae \\
\hline & Matonisporites sp. & Matoniaceae \\
\hline & Peromonolites vellosus (Partridge) Stover y Partridge, 1973. & Blechnaceae \\
\hline & Polypodiisporites inangahuensis (Couper 1953) Potonie, 1956. & Polypodiaceae \\
\hline & Retitriletes austroclavatidites (Cookson) Döring et al., 1963. & Lycopodiaceae \\
\hline & Retitriletes sp. & Lycopodiaceae \\
\hline & Trilites sp. & Dicksoniaceae \\
\hline & Verrucatosporites $\mathrm{sp}$. & Polypodiaceae \\
\hline
\end{tabular}




\begin{tabular}{|c|c|c|}
\hline \multicolumn{2}{|r|}{ TAXA } & AFINIDAD BOTÁNICA \\
\hline \multirow{14}{*}{ 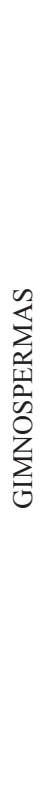 } & Araucariacites australis Cookson, 1947. & Araucariaceae \\
\hline & Araucariacites pergranulatus Volkheimer, 1968. & Araucariaceae \\
\hline & Araucariacites sp. & Araucariaceae \\
\hline & Dacrycarpites australiensis Cookson y Pike, 1953. & Podocarpaceae \\
\hline & Gamerroites psilasaccus (Archangelsky y Romero) Archangelsky, 1988. & Podocarpaceae \\
\hline & Gamerroites sp. & Podocarpaceae \\
\hline & Microcachryidites antarcticus Cookson, 1947. & Podocarpaceae \\
\hline & Phyllocladidites mawsonii (Cookson) Couper, 1953. & Podocarpaceae \\
\hline & Podocarpidites elegans Romero, 1977. & Podocarpaceae \\
\hline & Podocarpidites ellipticus Cookson, 1947. & Podocarpaceae \\
\hline & Podocarpidites marwickii Couper, 1953. & Podocarpaceae \\
\hline & Podocarpidites microreticuloidatus Cookson, 1947. & Podocarpaceae \\
\hline & Podocarpidites rugulosus Romero, 1977. & Podocarpaceae \\
\hline & Podocarpidites sp. & Podocarpaceae \\
\hline \multirow{19}{*}{ 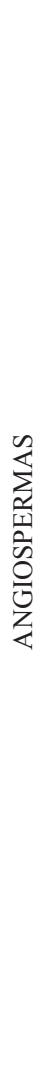 } & Liliacidites sp. & Liliaceae \\
\hline & Liliacidites variegatus Couper, 1953. & Liliaceae \\
\hline & Margocolporites sp. & Fabaceae \\
\hline & Monocolpites sp. & Arecaceae \\
\hline & Nothofagidites (tipo brassii) & Nothofagaceae \\
\hline & Nothofagidites (tipo fusca) & Nothofagaceae \\
\hline & Nothofagidites (tipo menziesii) & Nothofagaceae \\
\hline & Pandaniidites texus (Elsik) Kumar y Takahashi, 1991 & Pandanaceae \\
\hline & Peninsulapollis gillii (Cookson) Dettmann y Jarzen, 1988. & Proteaceae \\
\hline & Propylipollis pseudomoides (Stover) Dettman y Jarzen, 1996. & Proteaceae \\
\hline & Propylipollis sp. & Proteaceae \\
\hline & Proteacidites sp. & Proteaceae \\
\hline & Proteacidites subscabratus Couper, 1960. & Proteaceae \\
\hline & Psilatricolporites sp. & Fabaceae \\
\hline & Rousea sp. & Adoxaceae \\
\hline & Spinozonocolpites sp. & Arecaceae \\
\hline & Tetracolpites sp. & Oleaceae \\
\hline & Tricolpites sp. & Proteaceae \\
\hline & Triorites minor Couper, 1953. & Proteaceae \\
\hline
\end{tabular}




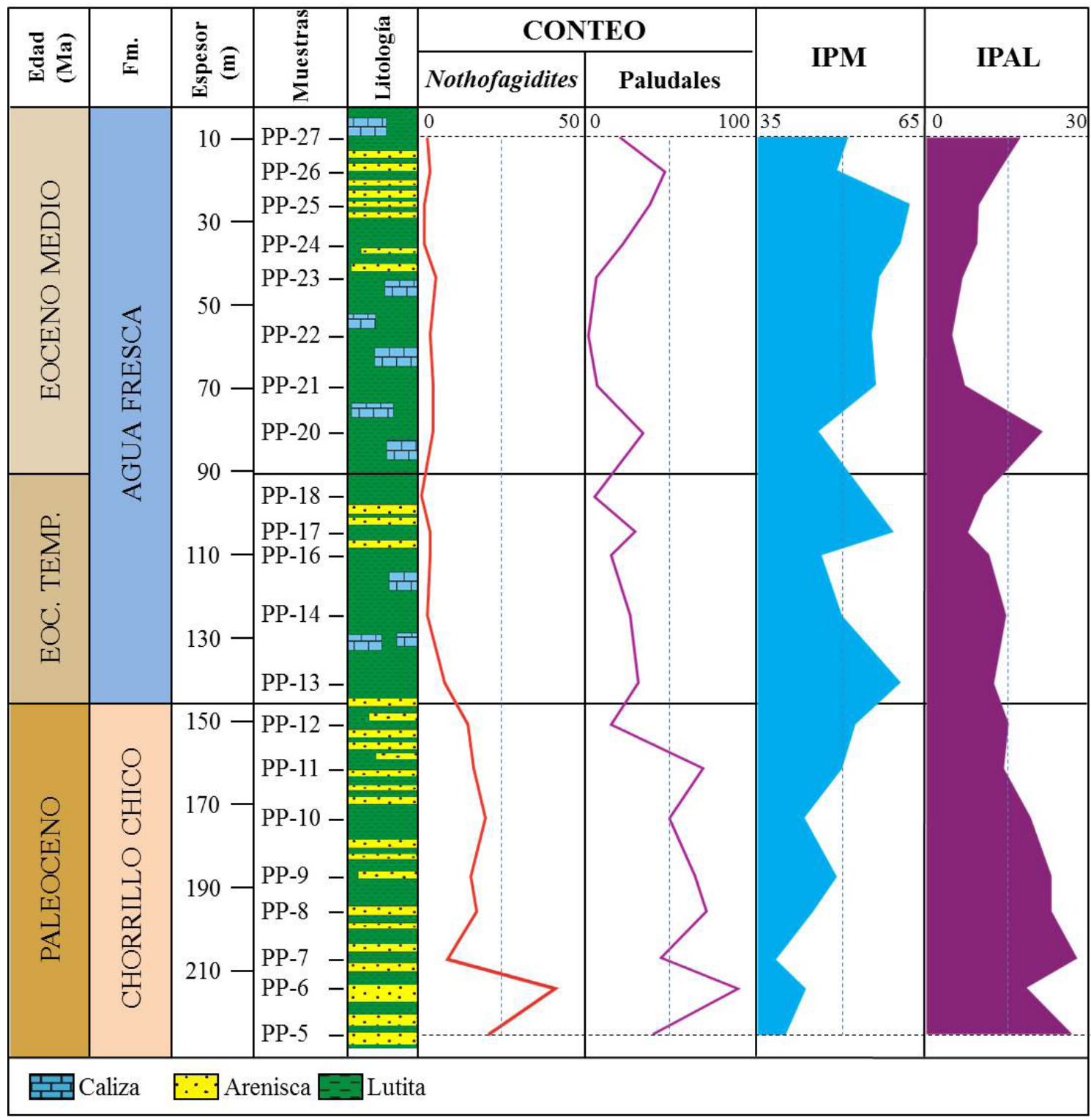

FIG. 2. Índices de palinomorfos. La litología y la posición estratigráfica de las muestras están indicadas en escala vertical. Se muestran los cambios cíclicos en: conteos absolutos de Nothofagidites y Paludales y los IPM (Índices de Palinomorfos Marinos) y de IPAL (Índice de Paludales).

IPM; esto se observa claramente en la Formación Chorrillo Chico durante el Paleoceno (Fig. 2).

\subsection{Comparación Regional de Asociaciones Palinológicas}

A fin de definir sus similitudes y diferencias, se comparan las asociaciones palinológicas presen- tadas en esta investigación, con otras asociaciones correlacionables cronológicamente, descritas con anteriordad para la Patagonia. Estas son la Formación Cerro Bororó: secciones en Las Plumas (Volkheimer et al., 2007) y Golfo San Jorge (Archangelsky, 1973, 1976; Archangelsky y Romero, 1974; Archangelsky y Zamaloa, 1986; Barreda y Palazzesi, 2007); Formación Salamanca (Archangelsky y Zamaloa, 1986); Forma- 
ción Huitrera: secciones en Confluencia y Nahuel Huapi Este (Báez et al., 1990; Melendi et al., 2003), y Formación Río Turbio: Sección Inferior y Superior (Archangelsky, 1972; Romero, 1977; Romero y Zamaloa, 1985; Romero y Castro, 1986). La ubicación regional de Punta Prat y las secciones usadas en esta comparación se muestran en la figura 3-A.

\subsubsection{Agrupamiento y Diversidad}

El análisis de agrupamientos ('clusters') de las asociaciones palinológicas muestra 4 grupos principales: 1. Formación Huitrera, 2. Formación Río Turbio, 3. formaciones Chorrillo Chico y Agua Fresca y 4. formaciones Salamanca y Cerro Bororó (Cuenca del Golfo San Jorge); la Formación Cerro Bororó (Las Plumas) se encuentra aislada de las agrupaciones (Fig. 3-B). En el grupo 3, los valores del Índice de Diversidad de Shannon (H') son muy similares; sin embargo, la Formación Chorrillo Chico presenta un valor ligeramente mayor $(4,06)$ que el de la Formación Agua Fresca $(3,97)$; esto se debe a que en las muestras paleocenas hubo mayor recuperación de especies, como por ejemplo Clavifera triplex, Klukisporites variegatus, Polypodiisporites inangahuensis, Araucariacites pergranulatus, Liliacidites variegatus y Pandaniidites texus, que no se encontraron presentes en las muestras eocenas. Las agrupaciones que presentan mayor similitud con las formaciones del grupo 3 son las formaciones Salamanca y Cerro Bororó (S. Jorge) del Daniano, y la Formación Río Turbio (inferior y superior) del Eoceno, los valores de H' en estas formaciones son mayores a 3,9, lo que indica mayores diversidades de especies, en comparación con la Formación Hui-
A.

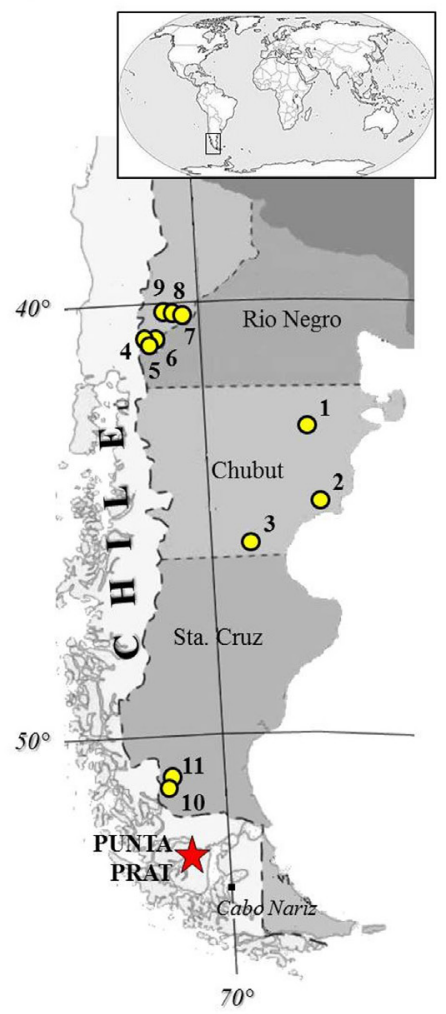

B.

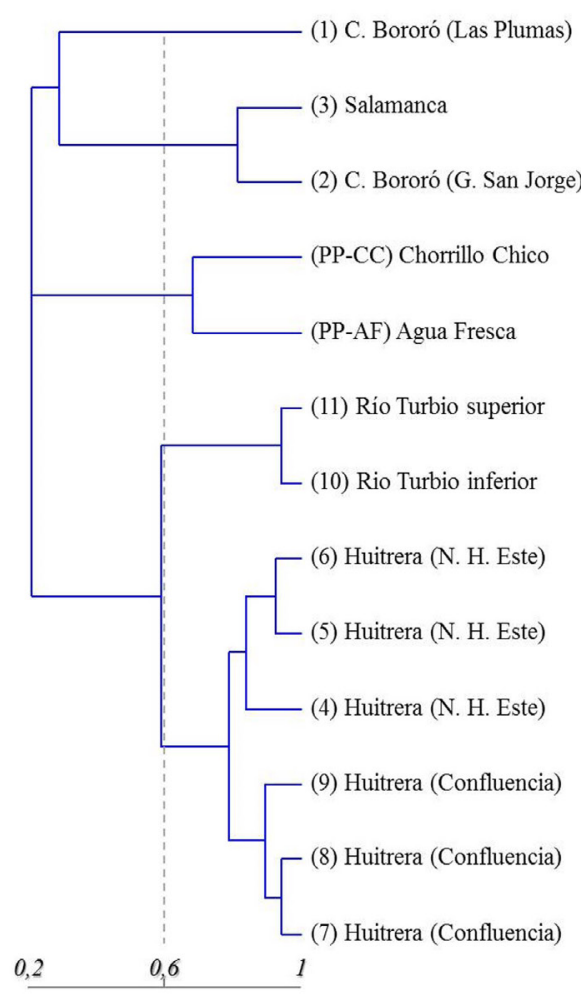

C.

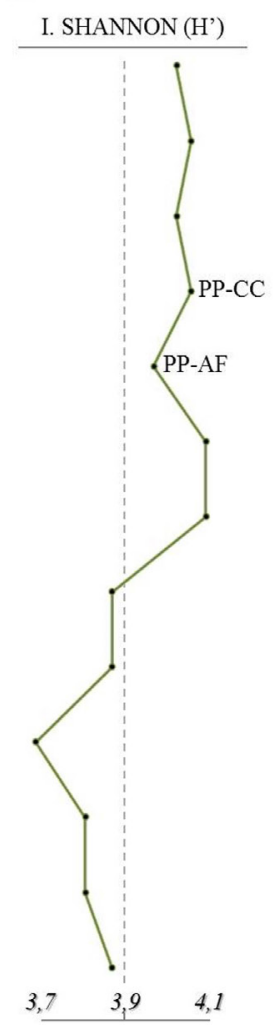

FIG. 3. A. Mapa de ubicación de Punta Prat y diferentes formaciones y/o localidades argentinas. Referencias: (1) Volkheimer et al., 2007; (2-3) Archangelsky, 1973, 1976; Archangelsky y Romero, 1974; Archangelsky y Zamaloa, 1986; (4-6) Melendi et al., 2003; (7-9) Báez et al., 1990; Melendi et al., 2003; (10-11) Archangelsky, 1972; Romero, 1977; Romero y Zamaloa, 1985; Romero y Castro, 1986. Punta Prat: Formación Chorrillo Chico (PP-CC) y Formación Agua Fresca (PP-AF). B. Dendograma de agrupamiento ('clusters') de las asociaciones palinológicas continentales, el Coeficiente de similitud de Jaccard y el programa PAST; modificado de Náñez et al., 2009. C. Gráfica del Índice de Diversidad de Shannon de las asociaciones. 
trera del Eoceno, cuyos valores de H' son menores a 3,9 (Fig. 3-C).

\subsubsection{Similitud}

Las asociaciones palinológicas descritas de las secciones paleógenas de Argentina presentan rangos de similitud que varían de 0,94 a 0,12. En la Formación Chorrillo Chico (PP-CC), los valores van de 0,68 a 0,15 y en la Formación Agua Fresca (PP-AF) de 0,68 a 0,12 ; en ambos casos el valor más alto corresponde a la similitud entre estas formaciones, seguido de Río Turbio (inferior y superior) del Eoceno, mientras que los valores más bajos corresponden a Cerro Bororó (Las Plumas) del Daniano (tabla 3). Estas relaciones concuerdan con lo indicado por el análisis de agrupamientos y por los valores de H'.

\section{Discusiones y conclusiones}

\subsection{Requerimientos ecológicos de los grupos continentales presentes en Punta Prat}

Esporas. En las dos formaciones aquí estudiadas, la abundante presencia de esporas (Fig. 4) refleja la existencia de condiciones húmedas. En el caso del género Deltoidospora ha sido relacionado con la clase Polypodiopsida a la que se asocian diversos géneros y familias como Cyatheaceae (Cyathea), Dicksoniaceae, y Schizaeaceae (Lygodium) (Raine et al., 2008; Cornou et al., 2012). Las esporas de Deltoidospora halladas se han relacionado con helechos de polipodiáceas. Este helecho se caracteriza por tener un crecimiento gregario y una distribución pantropical, principalmente en asociación con los hábitats de manglares (Collinson, 2002).

Gimnospermas. De los granos de polen encontrados en las dos formaciones aquí estudiadas (Fig. 5), las podocarpáceas, en general, requieren suelos bien drenados y se desarrollan en bosques montañosos y temperaturas templadas a frías (Mautino y Anzótegui, 2002). El género Podocarpidites es el más abundante de las podocarpáceas tanto en la Formación Chorrillo Chico como en la Formación Agua Fresca y está asociado al género viviente Podocarpus, el cual tiene una amplia distribución latitudinal, reconociéndose incluso en zonas montañosas de regiones tropicales (Barreda, 1996).

La especie bisacada Phyllocladidites mawsonii (Fig. 5-B), presente en ambas formaciones, está asociada con Lagarostrobus franklinii (Herngreen

TABLA 3. COEFICIENTES DE SIMILITUD DE JACCARD ENTRE DIFERENTES ASOCIACIONES PALINOLÓGICAS ARGENTINAS Y LAS FORMACIONES CHORRILLO CHICO Y AGUA FRESCA.

\begin{tabular}{lcccccccccccccc}
\hline & $\mathbf{1 1}$ & $\mathbf{1 0}$ & $\mathbf{9}$ & $\mathbf{8}$ & $\mathbf{7}$ & $\mathbf{6}$ & $\mathbf{5}$ & $\mathbf{4}$ & $\mathbf{3}$ & $\mathbf{2}$ & $\mathbf{1}$ & $\mathbf{P P}-\mathbf{C C}$ & $\mathbf{P P}-\mathbf{A F}$ \\
11 & 1,00 & 0,94 & 0,62 & 0,62 & 0,59 & 0,54 & 0,50 & 0,54 & 0,36 & 0,35 & 0,21 & 0,24 & 0,26 \\
10 & 0,94 & 1,00 & 0,67 & 0,67 & 0,64 & 0,59 & 0,54 & 0,59 & 0,37 & 0,36 & 0,21 & 0,24 & 0,26 \\
9 & 0,62 & 0,67 & 1,00 & 0,91 & 0,86 & 0,75 & 0,69 & 0,77 & 0,45 & 0,44 & 0,25 & 0,21 & 0,22 \\
8 & 0,62 & 0,67 & 0,91 & 1,00 & 0,94 & 0,82 & 0,75 & 0,85 & 0,49 & 0,46 & 0,25 & 0,21 & 0,23 \\
7 & 0,59 & 0,64 & 0,86 & 0,94 & 1,00 & 0,85 & 0,78 & 0,80 & 0,48 & 0,45 & 0,24 & 0,20 & 0,22 \\
6 & 0,54 & 0,59 & 0,75 & 0,82 & 0,85 & 1,00 & 0,92 & 0,83 & 0,47 & 0,44 & 0,24 & 0,20 & 0,22 \\
5 & 0,50 & 0,54 & 0,69 & 0,75 & 0,78 & 0,92 & 1,00 & 0,83 & 0,47 & 0,44 & 0,24 & 0,19 & 0,20 \\
4 & 0,54 & 0,59 & 0,77 & 0,85 & 0,80 & 0,83 & 0,83 & 1,00 & 0,53 & 0,50 & 0,26 & 0,20 & 0,21 \\
3 & 0,36 & 0,37 & 0,45 & 0,49 & 0,48 & 0,47 & 0,47 & 0,53 & 1,00 & 0,81 & 0,27 & 0,18 & 0,16 \\
2 & 0,35 & 0,36 & 0,44 & 0,46 & 0,45 & 0,44 & 0,44 & 0,50 & 0,81 & 1,00 & 0,33 & 0,18 & 0,16 \\
1 & 0,21 & 0,21 & 0,25 & 0,25 & 0,24 & 0,24 & 0,24 & 0,26 & 0,27 & 0,33 & 1,00 & 0,15 & 0,12 \\
\hline PP-CC & 0,24 & 0,24 & 0,21 & 0,21 & 0,20 & 0,20 & 0,19 & 0,20 & 0,18 & 0,18 & 0,15 & 1,00 & 0,68 \\
PP-AF & 0,26 & 0,26 & 0,22 & 0,23 & 0,22 & 0,22 & 0,20 & 0,21 & 0,16 & 0,16 & 0,12 & 0,68 & 1,00 \\
\hline
\end{tabular}




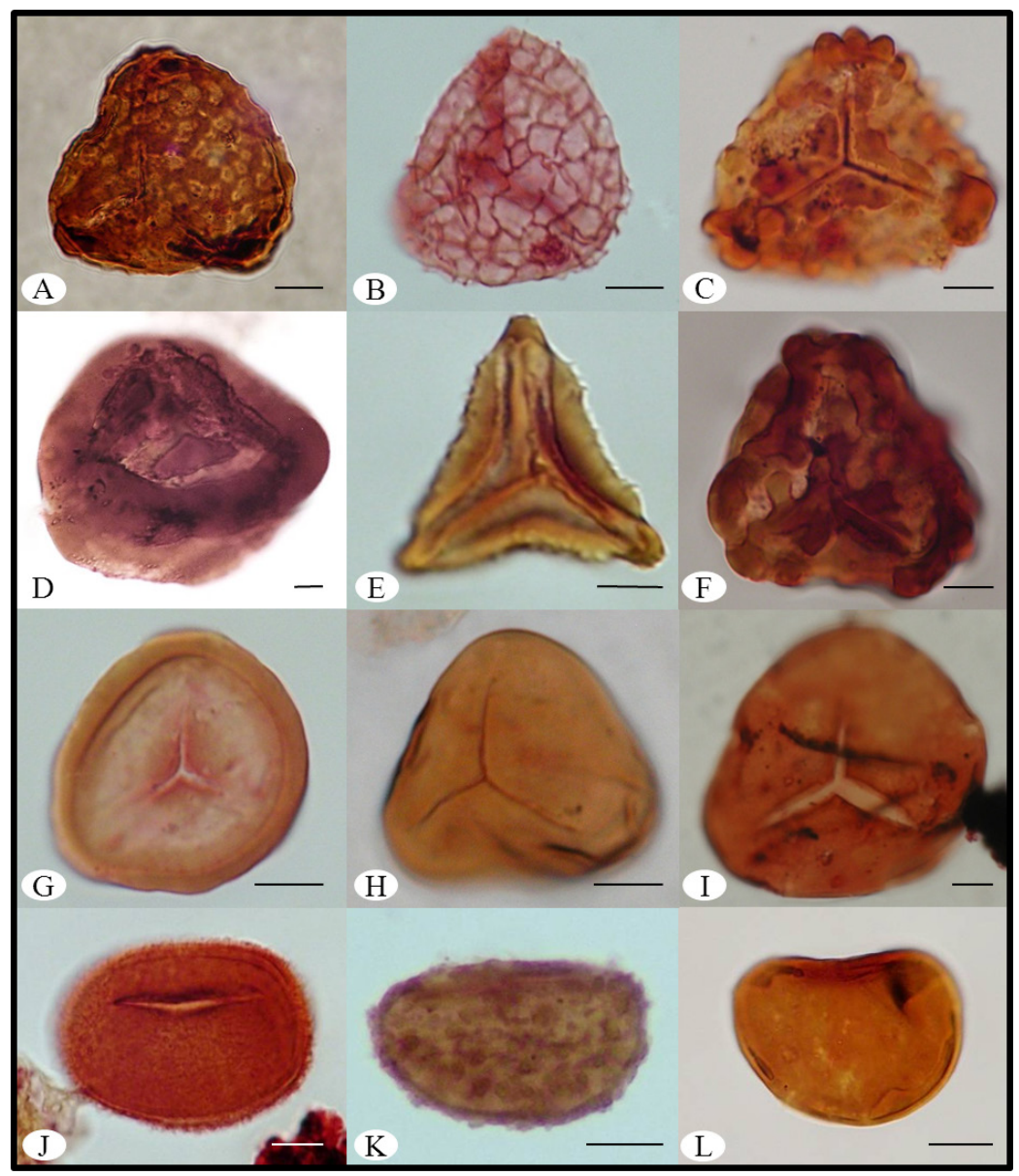

FIG. 4. Esporas de la localidad Punta Prat, Chile: A. Klukisporites sp. PP-17 (3981/5): H44/1, vista proximal; B. Retitriletes austroclavatidites (Cookson) Döring, Krutzsch, Mai y Schulz, 1963. PP-8 (3972/6): A32/3, vista proximal; C. Ischyosporites areapunctatis (Stuchlik) Barreda, 1996. PP5 (3969/6): O50, vista proximal; D. Cyatheacidites annulatus Cookson ex Potonie, 1956. PP-6 (3970/6): T44/2, vista proximal; E. Clavifera triplex (Bolkhovitina) Bolkhovitina, 1966. PP10 (3874/6): D39/3, vista proximal; F. Ischyosporites sp. PP-6 (3970/6): O31, vista proximal; G. Cingutriletes australis (Cookson) Archangelsky, 1972. PP-8 (3972/6): A35/2, vista proximal; H. Deltoidospora sp. aff. D. minor (Couper) Pocock 1970. PP-5 (3969/6): L35/4, vista proximal; I. Deltoidospora sp. PP-5 (3969/6): H41-2, vista proximal; J. Peromonolites vellosus (Partridge) Stover y Partridge, 1973. PP-8 (3972/6): A39, vista lateral; K. Polypodiisporites inangahuensis (Couper) Potonie, 1956. PP-6 (3970/4): L45, vista lateral; L. Laevigatosporites ovatus Wilson y Webster, 1946. PP-8 (3972/6): W45, vista lateral. Escala gráfica: A-L, barra $10 \mu \mathrm{m}$.

et al., 1996), que actualmente se desarrolla en zonas lluviosas, como el oeste de Tasmania, no requiere de suelos drenados por lo que su hábitat son las orillas de los ríos y llanos pantanosos, y se desarrollan bajo condiciones de clima templado (Melendi et al., 2003).

Las araucariáceas al igual que las podocarpáceas, en general, se desarrollan en zonas altas y climas templados-fríos. Sin embargo, son más adaptables y también podrían vincularse a áreas relativamente bajas (Quattrocchio et al., 2007) e incluso se han relacionado con ambientes costeros (Abbink, 1998) y/o comunidades palustres (Whitaker et al., 1992).

Angiospermas. Las angiospermas observadas están representadas en un 58\% por la familia Proteaceae, que son árboles o arbustos que requieren de suelos bien drenados. Los mayores conteos se presentan en el Paleoceno (Formación Chorrillo Chico) y disminuyen hacia el Eoceno (Formación Agua Fresca). 


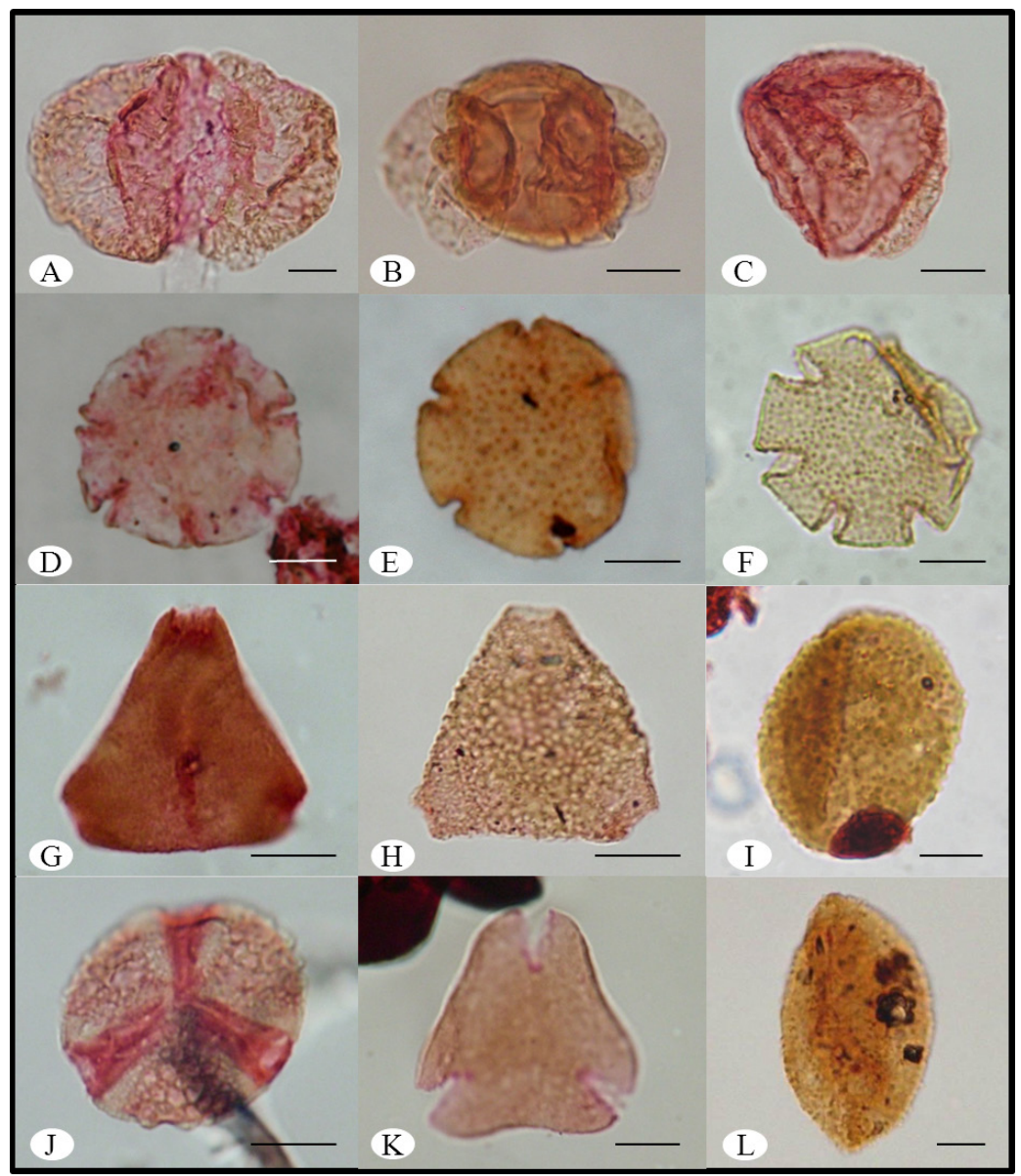

FIG. 5. Granos de polen de la localidad Punta Prat, Chile: A. Podocarpidites marwickii Couper, 1953. PP-6 (3970/6): W44-1, vista polar; B. Phyllocladidites mawsonii (Cookson) Couper, 1953. PP10 (3974/6): T42, vista polar; C. Dacrycarpites australiensis Cookson y Pike, 1953. PP10 (3974/6): U30, vista polar; D. Nothofagidites tipo 'ancestral' (N. kaitangataensis Couper) PP-5 (3969/6): R43-3, vista polar; E. Nothofagidites tipo fusca (N. waipawaensis Couper). PP-5 (3969/6): O38-4, vista polar; F. Nothofagidites tipo brassii (N. dorotensis Romero ) PP-5 (3969/6): R43-3, vista polar; G. Proteacidites subscabratus Couper, 1960. PP-6 (3970/6): Q41, vista polar; H. Propylipollis pseudomoides (Stover) Dettmann y Jarzen, 1996. PP-6 (3970/4): M46, vista polar; I. Pandanus texus (Elsik) Kumar y Takahashi, 1991: PP-7 (3971/1): H 45, vista distal; J. Margocolporites sp. PP-10 (3974/6): D44/3, vista polar; K. Peninsulapollis gillii (Cookson) Dettmann y Jarzen, 1988. PP-9 (3973/6): O32, vista polar; L. Liliacidites variegatus Couper, 1953. PP5 (3969/6): V32/1, vista distal. Escala gráfica: A-L, barra $10 \mu \mathrm{m}$.

En Argentina, los registros más antiguos de la familia Proteaceae son los correspondientes al Campaniano Tardío (Cretácico) de la Formación Los Almitos, Río Negro (Quattrocchio et al., 2007) con Peninsulapollis gilli. Esta especie presenta una gran similitud con la actual Beauprea (Dettmann y Jarzen, 1998; Prámparo et al., 2007).

Las nothofagáceas se asocian a zonas de alta humedad (Herngreen et al., 1996), y se han utilizado para indicar condiciones de clima templado (Romero,
1978; Quattrocchio y Volkheimer, 2000). El género Nothofagidites se asocia con Nothofagus, uno de los principales componentes de los bosques subantárticos actuales. Los primeros registros del género pertenecen al Cretácico tardío de la Antártica (Dettmann et al., 1990; Markgraf et al., 1996) y la Patagonia (Provincia de Río Negro), particularmente del Maastrichtiano Medio (Romero, 1973; Prámparo et al., 2007). Los primeros macrofósiles de Nothofagus en la Patagonia pertenecientes al Paleoceno (Iglesias et al., 2007) 
se caracterizan por tener grandes hojas semejantes a las actuales especies de Nueva Caledonia y, por lo tanto, pueden estar relacionados con climas cálidos y húmedos. Sin embargo, Nothofagus de hojas reducidas, apareció en la Patagonia a partir del Lutetiano (Quattrocchio et al., 2007) y están relacionados con clima templado a frío (Iglesias et al., 2011).

Varios autores (Kemp, 1976; Barreda, 1996, 1997), han mencionado que los requerimientos ecológicos del género Nothofagidites se pueden inferir por el tipo de grano de polen que lo representa. Se ha mencionado que el tipo brassii (Brassospora) se relaciona con climas templado-cálidos (mesotermales) y zonas más bajas en comparación con los tipos fusca (Fuscospora) y menziesii (Lophozonia), los cuales requieren de suelos bien drenados que generalmente se encuentran en zonas altas y de temperatura más baja.

Al igual que en el sur de Australia, en Sudamérica los climas fueron más cálidos durante el Paleoceno Tardío al Neógeno Temprano que en la actualidad. En efecto, las especies vivientes de las angiospermas encontradas, relacionadas con la foresta lluviosa de Nothofagus tipo brassii (Brassospora) son mesotermales (templado-cálido) a megatermales (subtropical-tropical) (M. Mac Phail, comunicación personal, 2012). En el sur de Chile ( $\left.46^{\circ} \mathrm{S}\right)$, la Formación Ligorio Marquez (Suárez et al., 2000; Troncoso et al., 2002) presenta una diversidad significativa de la familia megatermal Lauraceae (Suárez et al., 2000), sugiriendo también que las condiciones cálidas prevalecieron en el sur de la Patagonia hasta el Paleoceno Tardío?-Eoceno Temprano.

Se ha reconocido, además, $N$. kaitangataensis (Te Punga, Romero, 1973) (Fig. 5-D). Estas formas exclusivamente fósiles, no ubicables dentro de los tres grupos reconocidos en el polen actual, son agrupadas como Nothofagidites 'ancestral' (Dettmann et al., 1990). En América del Sur, este grupo está representado por una sola especie, $N$. kaitangataensis (Te Punga, Romero, 1973), registrada del Maastrichtiano al Eoceno Medio, entre Punta Arenas ( $28 \mathrm{~km}$ al este de Punta Prat) y Tierra del Fuego (Romero y Zamaloa, 1997), presente también en Nueva Zelanda y Australia (Dettmann et al., 1990).

En Punta Prat, se observa una disminución en la proporción general del Paleoceno (85\%) hasta el Eoceno Medio (15\%) en los conteos de Nothofagidites (Fig. 2). En la mayoría de las muestras predominan los tipo fusca y menziesii, los cuales han sido asociados a climas templados-fríos. Aunque que en el intervalo basal del Eoceno Temprano y la parte más alta del intervalo estudiado, hay una ligera predominancia del tipo brassii. Estos cambios sugieren que en la cuenca Magallanes-Austral, todos los Nothofagidites disminuyeron su número por pérdida de hábitat debido a la invasión marina en el evento transgresivo del Paleoceno al Eoceno.

\subsection{Paleoecología continental de Punta Prat}

La paleoecología en la localidad Punta Prat durante el Paleógeno puede inferirse sobre la base de las asociaciones de los palinomorfos continentales observados en las formaciones Chorrillo Chico y Agua Fresca. Estos conjuntos palinológicos los constituyen elementos de las familias Podocarpaceae, Proteaceae y Nothofagaceae asociadas a helechos (Schizaeaceae, Polypodiaceae y Dicksoniaceae), cuyos requerimientos ecológicos están relacionados con alta humedad. La presencia de la familia Pandanaceae solamente en la Formación Chorrillo Chico asociada a Phyllocladidites mawsonii, Spinozonocolpites (asociado actualmente a Nypa), Nothofagidites tipo brassii y Deltoidospora, indica hábitats de humedal en el Paleoceno, mientras que su ausencia en el Eoceno señala desaparición de estos ambientes de zonas bajas, probablemente relacionada con una transgresión.

El género Nothofagidites es común en las muestras de ambas formaciones expuestas en Punta Prat y su distribución permite la interpretación de cambios ambientales. La localidad Pampa de Jones (Formación Huitrera en la Provincia de Neuquén, Argentina), es la única localidad datada radiométricamente en la Argentina, como Eoceno Temprano (54,24 Ma) (Wilf et al., 2010). En esta localidad, así como en el centro y norte de la Patagonia, durante el calentamiento del Eoceno Temprano, no se han reportado granos de polen de Nothofagidites (Troncoso y Romero, 1998; Melendi et al., 2003; Volkheimer et al., 2006; Barreda y Palazzesi, 2007; Wilf et al., 2010).

En cambio en Punta Prat, Nothofagidites se encuentra presente desde Paleoceno (Formación Chorrillo Chico) hasta el Eoceno Medio (Formación Agua Fresca). Esta presencia sugiere que la cuenca de Magallanes-Austral pudo estar influenciada con el aporte proveniente de la Antártica, ya que la parte sur de la Patagonia se mantuvo unida a la Antártica Occidental durante un largo período (Romero, 1986; Nullo y Combina, 2011), por lo que su evolución fue, 
en parte, independiente de resto de Gondwana. Esta independencia pudo favorecer al registro y desarrollo de Nothofagidites primero en la parte más austral de Sudamérica y posteriormente en el centro y norte de la Patagonia, probablemente a partir del Eoceno Medio Tardío (Formación Río Turbio).

Del Paleoceno al Eoceno Medio los conteos de Nothofagidites en Punta Prat disminuyen, lo que implica un cambio en las condiciones ambientales, posiblemente reflejando el Máximo Termal del Paleoceno-Eoceno (MTPE) (Zachos et al., 2001), que aumentó la temperatura, inicialmente con lluvias escasas, y posteriormente con alta humedad (Wing et al., 2005). Estos cambios ambientales sugieren que la reducción en el tamaño de las hojas de Nothofagus (Iglesias et al., 2007) del Paleoceno al Eoceno pudo ser el resultado de su adaptación ante el calentamiento y la escasa precipitación, característicos del MTPE. Es probable que esta adaptación haya favorecido posteriormente a las nothofagáceas, permitiendo su desarrollo y permanencia hasta la actualidad en el sur de la Patagonia.

Por otra parte, al analizar el comportamiento descendente de los conteos de los tres tipos de Nothofagidites en las formaciones Chorrillo Chico y Agua Fresca, se infiere que el aumento en la temperatura global del Paleoceno-Eoceno (MTPE), no eliminó los granos de polen de Nothofagidites tipo fusca y menziesii (templados-fríos) sino solo disminuyó su número, mientras que los tipo brassii (templadoscálidos) pudieron haber sido favorecidos por el calentamiento, pero debido a que forman parte de las especies paludales, estos perdieron su hábitat, disminuyendo su número por la invasión marina en el evento transgresivo del Paleoceno al Eoceno.

Los registros de los granos de polen de la familia Pandanaceae también nos permite interpretar cambios importantes durante la depositación de los sedimentos paleógenos de Punta Prat. En esta localidad, esta familia se encuentra representada por el género Pandaniidites, el cual se ha registrado en Patagonia y en la cuenca de Salta en el Daniano. Globalmente, el registro más antiguo para el género es del Maastrichtiano de Saskatchewan, Canadá (Nichols et al., 1986). Los cambios climáticos paulatinos durante el Cenozoico provocaron su migración a áreas tropicales-subtropicales, donde se desarrolla actualmente (Prámparo et al., 2007).

En Punta Prat Pandaniidites texus se registra hasta el Paleoceno Tardío (Daniano Tardío a Selan- diano Tardío) en la Formación Chorrillo Chico. Esta presencia sugiere que las familias Pandanaceae y Arecaceae (Spinizonocolpites) estarían asociada a la generación de nuevos hábitats, debido a la regresión paleocena. Además, la ausencia de Pandaniidites texus en la Formación Agua Fresca (Eoceno) se podría relacionar con la desaparición de zonas bajas durante la transgresión. Aunque no puede descartarse la idea de que el calentamiento del MTPE haya influido, es improbable que estos taxa que actualmente se encuentran en latitudes bajas hayan desaparecido por el aumento en temperatura.

Durante el Eoceno Temprano en la Formación Agua Fresca, Phyllocadidites mawsonii junto con nothofagáceas y proteáceas, de forma lineal, presentan una disminución en los conteos hacia la base del Eoceno Medio, a partir de esta edad hacia el tope de la sección Phyllocadidites mawsonii, junto con las proteáceas y en menor medida las araucarias presentan un ligero incremento, lo que sugiere el inicio del restablecimiento de sus hábitats. Sin embargo, de forma general las fluctuaciones de estas familias con requerimientos de mediana a alta humedad reflejan condiciones similares a las que presentan las nothofagáceas posteriormente al MTPE.

\section{3. Índice de Palinomorfos Marinos (IPM) e Índice de Paludales (IPAL)}

En la sucesión marina paleógena estudiada, representada por las formaciones Chorrillo Chico y Agua Fresca, se observa una continuidad en la granulometría, es decir, que no se advierten depósitos clásticos que muestren un cambio brusco en la litología; esta homogeneidad puede estar relacionada con el hecho de que Punta Prat se ubica en el depocentro de la Cuenca Magallanes-Austral. Se ha propuesto que el pasaje Paleoceno-Eoceno se produce dentro de un nivel eustático bajo, que se manifiesta en la Patagonia con una pronunciada regresión y el consecuente desarrollo de una marcada discontinuidad en las cuencas patagónicas (Malumián, 1999).

La ausencia del género de dinoflagelado Apectodinium (Quattrocchio, 2009) indica un posible hiato-laguna en el límite Paleoceno-Eoceno en el área estudiada. La relación de la Formación Chorrillo Chico con la suprayacente Formación Agua Fresca, en el área de estudio es mediante una paraconcordancia. Otros autores también interpretan la presencia de una discontinuidad regional a mediados del Tha- 
netiense (Paleoceno Tardío) en la parte superior de la Formación Chorrillo Chico (Biddle et al., 1986).

El análisis estadístico de palinomorfos, muestra que los conteos y riqueza de especies continentales presentan una tendencia a disminuir hacia la parte superior de la secuencia sedimentaria (parte alta de la Formación Agua Fresca), mientras que el IPM aumenta. Esta combinación de características sugiere una transgresión marina a finales del Paleoceno (Formación Chorrillo Chico), la que se enfatiza durante el Eoceno (Formación Agua Fresca). El comportamiento inverso del IPAL con respecto al IPM sugiere que los taxa paludales cercanos a la costa pierden su hábitat por la invasión marina en eventos transgresivos.

\section{4. Índice de Similitud}

Los índices de similitud en las formaciones Chorrillo Chico y Agua Fresca son menores a 0,68 lo que indica marcadas diferencias entre las asociaciones paleocenas y eocenas de estas formaciones y las de Argentina. Esta diferencia es particularmente evidente con la sucesión expuesta en Cerro Bororó (Las Plumas) del Paleoceno, debido a que en el nivel muestreado en esta localidad de Argentina, se ha reportado la presencia de las familias Ephedraceae, Gunneraceae, Ericaceae y esporas de la familia Salviniaceae (Volkheimer et al., 2007), las cuales no están presentes en las asociaciones aquí estudiadas.

De las asociaciones paleógenas analizadas de la literatura, la que presenta el mayor índice de similitud a las formaciones Chorrillo Chico $(0,24)$ y Agua Fresca $(0,26)$ es la Formación Río Turbio (Superior e Inferior) de edad eocena (Archangelsky, 1972; Romero, 1977; Romero y Zamaloa, 1985; Romero y Castro, 1986), debido a la presencia de Podocarpaceae, Nothofagaceae, el género Phyllocladidites, y en menor proporción Araucariaceae y Proteaceae. También se registran esporas de helechos principalmente de las familias Schizaeaceae y Polypodiaceae. Sin embargo, el índice de similitud es bajo $(0,26$ y 0,24$)$ y por lo tanto no significativo. Esto se debe a que en la Formación Río Turbio se registran por ejemplo, las familias Ephedraceae y Juglandaceae, las que están ausentes en Punta Prat.

Se sugiere que los depósitos de la Formación Agua Fresca serían previos a la depositación de la Formación Río Turbio (Eoceno Medio Tardío) en la que se verifica la expansión del bosque de Nothofagus (Romero, 1973) no registrado en la Formación Agua Fresca (Eoceno Temprano a Medio) aquí estudiada.

Las asociaciones palinológicas de Punta Prat representan los primeros registros de palinomorfos continentales de esta sucesión y caracterizan las condiciones paleoambientales y paleoclimáticas durante el Paleógeno en la Patagonia chilena. Las mismas se incluirían en la Paleoflora Gondwánica (Formación Chorrillo Chico) y la Paleoflora Subtropical Gondwánica (Formación Agua fresca) que reflejan condiciones tropicales relacionadas con un evento cálido y húmedo del Paleoceno-Eoceno (Hinojosa 2005).

Considerando la riqueza y abundancia de esporomorfos registrados en las formaciones Chorrillo Chico y Agua Fresca que indican proximidad al área de aporte continental, principalmente la gran abundancia de esporas indicativas de proximidad a afluentes fluvio deltaicos, dado que estas son producidas en menor número que el polen anemófilo $y$ tienden a ser transportadas menos eficientemente, sumado a la riqueza y abundancia de dinoquistes que indican la depositación en un medio marino y de plataforma externa por la presencia del género Impagidinium (Wrenn y Kokinos, 1986) en toda la sección analizada, se sugiere, principalmente para la Formación Chorrillo Chico, que sus litofacies corresponderían a flujos hiperpícnicos (J.J. Ponce, comunicación personal, 2012), es decir, descargas fluviales originadas en el continente con agua dulce intersticial (turbiditas extracuencales tipo E) (Zavala, 2012). No existiendo en la bibliografía mundial (R. Tyson, comunicación personal, 2012), estudios detallados sobre la palinología en ambos sistemas, ni estudios sedimentológicos de detalle en el área de estudio se deja abierta la presente discusión.

\section{Agradecimientos}

Se agradece al Consejo Nacional de Ciencia y Tecnología (CONACYT) en México por el apoyo financiero a la primera autora durante su estancia en la Universidad Nacional del Sur (UNS). La investigación fue financiada por el Consejo Nacional de Investigaciones Científicas y Técnicas (CONICET) y la Secretaria de Ciencia y Técnica de la UNS, Bahía Blanca, Argentina. Se agradece la ayuda en la preparación de las muestras a la Sra. N.M. Choo de la Universidad de Saskatchewan, Canadá. Especial agradecimiento a los Dres. M.C. Zamaloa, 
J.L. García-Massini, R. Tyson, J.J. Ponce y M. Mac Phail, a los revisores y editores por su valiosa contribución en la mejora de este trabajo.

\section{Referencias}

Abbink, O.A. 1998. Palynological investigations in the Jurassic of the North Sea region. Ph.D. Thesis (Inédito), Utrecht University: 192 p. Utrecht.

Archangelsky, S. 1972. Esporas de la Formación Río Turbio (Eoceno). Provincia de Santa Cruz. Revista del Museo de La Plata (Nueva Serie), Paleontología 6: 65-100.

Archangelsky, S. 1973. Palinología del Paleoceno de Chubut. I. Descripciones sistemáticas. Ameghiniana 10: 339-399.

Archangelsky, S. 1976. Palinología del Paleoceno de Chubut. III Análisis numérico. Ameghiniana 13: 169-184.

Archangelsky, S.; Romero, E.J. 1974. Polen de gimnospermas (coniferas) del Cretacico Superior y Paleoceno de Patagonia. Ameghiniana 11: 217-236.

Archangelsky, S.; Zamaloa, M.C. 1986. Nuevas descripciones palinológicas de las Formaciones Salamanca y Bororó, Paleoceno de Chubut (República Argentina). Ameghiniana 23 (1-2): 35-46.

Báez, A.M.; Zamaloa, M. del C.; Romero, E. 1990. Nuevos hallazgos de microfloras y anuros paleógenos en el noroeste de Patagonia: implicancias paleoambientales y paleobiogeográficas. Ameghiniana 27: 83-94.

Barbeau, D.L.; Olivero, E.B.; Swanson-Hysell, N.L.; Zahid, K.; Murray, K.E.; Gehrels, G.E. 2009. Detrital-zircon geochronology of the eastern Magallanes foreland basin: Implications for Eocene kinematics of the northern Scotia Arc and Drake Passage. Earth and Planetary Science Letters 284: 489-503.

Barreda, V.D. 1996. Bioestratigrafía de polen y esporas de la Formación Chenque, Oligoceno Tardío?-Mioceno de las provincias de Chubut y Santa Cruz, Patagonia, Argentina. Ameghiniana 33: 35-96.

Barreda, V.D. 1997. Palynomorph assemblage of the Chenque Formation, Late Oligocene?-Miocene from Golfo San Jorge basin, Patagonia, Argentina. Terrestrial algae, trilete and monolete spores. Ameghiniana 34 (1): 69-80.

Barreda, V.D.; Palazzesi, L. 2007. Patagonian vegetation turnovers during the Paleogene-Early Neogene: Origin of arid-adapted floras. The Botanical Review 73: 31-50.

Biddle, K.T.; Uliana, R.M.; Mitchum, R.M. Jr.; Fitzgerald, M.G.; Wright, R.C. 1986. The stratigraphy and structural evolution of the central and eastern Magallanes Basin, southern South America. Special Publications of the American Association of Sedimentologists 8: 41-61. Collinson, M.E. 1978. Dispersed fern sporangia from the British Tertiary. The Annals of Botany 42 (1): 233-250. Collinson, M.E. 2002. The ecology of Cainozoic ferns. Review of Palaeobotany and Palynology 119: 51-68. Cornou, M.E.; Martínez, M.A.; Quattrocchio, M.E.; Asensio, M.A. 2012. Estudio palinológico de esporas de la Formación Salto del Macho, Paleógeno de la Cuenca de Nirihuau, Argentina. Ameghiniana 49: 1-11.

Dalziel, I.W.D.; De Wit, M.F.; Palmer, K.F. 1974. Fossil marginal basin in the southern Andes. Nature 50: 291-294.

Decat, J.; Pomeyrol, R. 1931. Informe geológico sobre las posibilidades petrolíferas de la Región Magallánica. Boletín Minero, Sociedad Nacional de Minería 389 (43): 763-772.

Dettmann, M.E.; Jarzen, D.M. 1998. The early history of the Proteaceae in Australia: the pollen record. Australian Systematic Botany 11: 401-438.

Dettmann, M.E.; Pocknall, D.T.; Romero, E.J.; Zamaloa, M.C. 1990. Nothofagidites Erdtman ex Potonié 1960: a catalogue of species with notes on the palaeogeographic distribution of Nothofagus B1 (southern beech). New Zealand Geological Survey, Palaeontological Bulletin 60: 1-79.

García-Massini, J.L.; Jacobs, B.F.; Pan, A.; Tabor, N.; Kappelman, J. 2006. The occurrence of the fern Acrostichum in successional volcanic and fluviolacustrine strata in the Oligocene of the northwestern Ethiopian Plateau. International Journal of Plant Sciences 167: 909-918.

Ghiglione, M.C.; Ramos, V.A.; Cristallini, E.O. 2002. Estructura y estratos de crecimiento en la faja plegada y corrida de los Andes fueguinos. Revista Geológica de Chile 29 (1): 17-41.

Halpern, M.; Rex, D.C. 1972. Time of folding of the Yahgan Formation and age of the Tekenika beds, southern Chile, South America. Geological Society of America, Bulletin 83 (6): 1881-1886.

Hammer, R.; Harper, D.A.T.; Ryan, P.D. 2001. PAST: Paleontological Statistics software package for education and data analysis. Palaeontología Electronica 4 (1): $1-9$.

Helenes, J.; De-Guerra, C.; Vásquez, J. 1998. Palynology and Chronostratigraphy of the Upper Cretaceous in the subsurface of the Barinas area, western Venezuela. American Association of Petroleum Geologists Bulletin 82 (7): 1308-1328.

Herngreen, G.F.W.; Kedves, M.; Rovnina, L.V.; Smirnova, S.B. 1996. Cretaceous palynofloral provinces: a review. In 
Palynology: Principles and Applications (Jansonius, J.; McGregor, D.C.; editores). American Association of Statigraphic Palynologists Foundation 3: 1157-1188.

Hill, R.S.; Read, J. 1991. A revised infrageneric classification of Nothofagus (Fagaceae). Botanical Journal of the Linnean Society 105: 37-72.

Hinojosa, L.F. 2005. Cambios climáticos y vegetacionales inferidos a partir de paleofloras cenozoicas del sur de Sudamérica. Revista Geológica de Chile 32 (1): 95-115. Iglesias, A.; Wilf, P.; Johnson, K.R.; Zamuner, A.B.; Cúneo, N.R.; Matheos, S.D.; Singer, B.S. 2007. A Paleocene lowland macroflora from Patagonia reveals significantly greater richness than North American analogs. Geology 35 (10): 947-950.

Iglesias, A.; Artabe, A.E.; Morel, E.M. 2011. The evolution of Patagonian climate and vegetation from the Mesozoic to the present. Biological Journal of the Linnean Society 103: 409-422.

Kemp, E.M. 1976. Early Tertiary pollen from Napperby, central Australia. Bureau of Mineral Resources journal of Australian geology and geophysics 1: 109-114.

Malumián, N. 1999. La sedimentación y el volcanismo terciario en la Patagonia extraandina. In Geología Argentina (Caminos, R.; editor). Instituto de Geología y Recursos Minerales, Anales 29: 557-612.

Malumián, N.; Náñez, C. 2011. The Late CretaceousCenozoic transgressions in Patagonia and the Fuegian Andes: foraminifera, paleoecology and paleogeography. Biological Journal of the Linnean Society 103: 269-288.

Marenssi, S.A.; Casadío, S.; Santillana, S.N. 2003. Estratigrafía y sedimentología de las unidades del Cretácico superior-Paleógeno aflorantes en la margen sureste del lago Viedma, provincia de Santa Cruz, Argentina. Revista de la Asociación Geológica Argentina 58 (3): 403-416.

Markgraf, V.; Romero, E.J.; Villagrán, C. 1996. History and paleoecology of South American Nothofagus forests. In The ecology and biogeography of Nothofagus forests (Veblen, T.T.; Hill, R.S.; Read, J.; editores). Yale University Press, New Haven: 354-386.

Martínez-Pardo, R. 1971. Relaciones cronoestratigráficas a lo largo del Territorio Chileno durante el Cenozico. Asociación Geológica de Chile, Geochile: 35-43.

Mautino, L.R.; Anzótegui, L.M. 2002. Palinología de la Formación Chiquimil (Mioceno Superior), en Río Vallecito, provincia de Catamarca, Argentina. Parte 2. Polen. Ameghiniana 39: 257-270.

Melendi, D.L.; Scafati, L.H.; Volkheimer, W. 2003. Palynostratigraphy of the Paleogene Huitrera Formation in NW Patagonia, Argentina. Neues Jahrbuch für Geologie und Paläeontologie, Abhandlungen 228: 205-273.

Mpodozis, C.; Ramos, V.A. 2008. Tectónica jurásica en Argentina y Chile: extensión, subducción oblicua, rifting, deriva y colisiones? Revista de la Asociación Geológica Argentina 63 (4): 481-497.

Náñez, C.; Quattrocchio, M.; Ruiz, L. 2009. Palinología y micropaleontología de las Formaciones San Julián y Monte León (Oligoceno-Mioceno Temprano) en el subsuelo de cabo Curioso, provincia de Santa Cruz, Argentina. Ameghiniana 46 (4): 669-693.

Narváez, P.L. 2009. Palinoestratigrafía, paleoambientes y cambios climáticos durante el Cretácico final y Paleógeno de la Cuenca del grupo Salta, República Argentina. Tesis doctoral (Inédito), Universidad Nacional de Cuyo: 229 p. Mendoza.

Natland, N.L.; González, E.; Cañon, A.; Ernst, M. 1974. A system of stages for correlation of Magallanes Basin sediments. Geological Society of America Memoir 139: $126 \mathrm{p}$.

Nichols, D.J.; Jarzen, D.M.; Orth, C.J.; Oliver, P.Q. 1986. Palynological and Iridium Anomalies at CretaceousTertiary Boundary, South-Central Saskatchewan. Science 231: 714-717.

Nullo, F.; Combina, A. 2011. Paleogeography and continental deposits of Patagonia, from the Late Cretaceous to the Pliocene. Biological Journal of the Linnean Society 103: 289-304.

Olivero, E.B.; Malumián, N. 1999. Eocene stratigraphy of southeastern Tierra del Fuego Island, Argentina. American Association of Petroleum Geologists, Bulletin 83 (2): 295-313.

Olivero, E.B.; Malumián, N. 2008. Mesozoic-Cenozoic stratigraphy of the Fuegian Andes, Argentina. Geológica Acta 6: 5-18.

Olivero, E.B.; Martinioni, D.R. 1996. Late Albian inoceramid bivalves from the Andes of Tierra del Fuego. Age implications for the closure of the Cretaceous marginal basin. Journal of Paleontology 70: 272-274.

Otero, R.A.; Torres, T.; Le Roux, J.P.; Hervé, F.; Fanning, C.M.; Yury-Yáñez, R.E.; Rubilar-Rogers, D. 2012. A Late Eocene age proposal for the Loreto Formation (Brunswick Peninsula, southernmost Chile), based on fossil cartilaginous fishes, paleobotany and radiometric evidence. Andean Geology 39 (1): 180-200.

Prámparo, M.B.; Quattrocchio, M.; Gandolfo, M.A.; Zamaloa, M.; Romero, E. 2007. Historia evolutiva de las angiospermas (Cretácico-Paleógeno) en Argentina a través de los registros paleoflorísticos. Asociación 
Paleontológica Argentina. Ameghiniana, Publicación Especial 11: 157-172.

Prieto, X.; Moraga, J. 1990. El Terciario Inferior de los ríos Rasmussen y Catalina, Tierra del Fuego, Magallanes. In Simposio sobre el Terciario de Chile, No. 2, Actas: 259-266. Concepción.

Quattrocchio, M.E. 2009. Paleogene Dinoflagellate Cysts from Punta Prat, Southern Chile Palynology 33 (1): 141-156.

Quattrocchio, M.E.; Sarjeant, W. 2003. Dinoflagellates from the Chorrillo Chico Formation (Paleocene) of southern Chile. Ameghiniana 40 (2): 129-153.

Quattrocchio, M.E.; Volkheimer, W. 2000. Danian paleophytogeoprovinces and their flora in Argentina. Revista Española de Paleontología 15 (1): 3-11.

Quattrocchio, M.E.; Martínez, M.A.; Volkheimer, W. 2007. Las floras jurásicas de la Argentina. Asociación Paleontológica Argentina. Ameghiniana, Publicación Especial 11: 87-100.

Raine, J.I.; Mildenhall, D.C.; Kennedy, E.M. 2008. New Zealand fossil spores and pollen: an illustrated catalogue. 3rd. edition. GNS Science miscellaneous series 4. $1 \mathrm{CD}$.

Romero, E.J. 1973. Polen fósil de 'Nothofagus' ('Nothofagidites') del Cretácico y Paleoceno de Patagonia. Revista del Museo de La Plata, nueva serie, Paleontología 7: 291-303.

Romero, E.J. 1977. Polen de gimnospermas y fagáceas de la Formación Río Turbio (Eoceno), Santa Cruz, Argentina. Fundación para la Educación, la Ciencia y la Cultura: 219 p. Buenos Aires.

Romero, E.J. 1978. Paleoecología y paleofitogeografía de las tafofloras del Cenofítico de Argentina y áreas vecinas. Ameghiniana 15: 209-227.

Romero, E.J. 1986. Fossil evidence regarding the evolution of Nothofagus blume. Annals Missouri Botanical Garden 73 (2): 276-283.

Romero, E.J.; Castro, M.T. 1986. Material fúngico y granos de polen de angiospermas de la Formación Río Turbio (Eoceno), provincia de Santa Cruz, República Argentina. Ameghiniana 23: 101-118.

Romero, E.J.; Zamaloa, M.C. 1985. Polen de angiospermas de la Formación Río Turbio (Eoceno), provincia de Santa Cruz, Argentina. Ameghiniana 22: 43-51.

Romero, E.J.; Zamaloa, M.C. 1997. Clave para la identificación de las especies y puestas a punto del registro de Nothofagidites en América del sur. Ameghiniana 34 (2): 207-214.

Sánchez, A.; Pavlishina, P.; Godoy, E.; Hervé, F.; Fanning, C.M. 2010. On the presence of Upper Paleocene rocks in the foreland succession at Cabo Nariz, Tierra del Fuego, Chile: geology and new palynological and U-Pb data. Andean Geology 37 (2): 413-432.

Shannon, C.E.; Weaver, W. 1949. The Mathematical Theory of Communication. The University Illinois Press, Urbana: 28 p. U.S.A.

Suárez, M.; De la Cruz, R.; Troncoso, A. 2000. Tropical/ subtropical Upper Paleocene-Lower Eocene fluvial deposits in eastern central Patagonia, Chile (46 $\left.45^{\circ} \mathrm{S}\right)$. Journal of South American Earth Sciences 13: 527-536.

Thomas, C.R. 1949. Geology and petroleum exploration in Magallanes province, Chile. Bulletin of the American Association of Petroleum Geologists 33: 1553-1578.

Torres-Carbonell, J.P. 2010. Control tectónico en la estratigrafía y sedimentología de secuencias sinorogénicas del Cretácico Superior-Paleógeno de los Andes Fueguinos. Tesis doctoral (Inédito), Universidad Nacional del Sur, Departamento de Geología: 384 p. Bahía Blanca, Argentina.

Traverse, A. 1994. Sedimentation of Organic Particles, Cambridge University Press, Great Britain: 544 p. U.S.A.

Troncoso, A.; Romero, E.J. 1998. Evolución de las comunidades florísticas en el extremo sur de Sudamérica durante el Cenofítico. In Proceedings of the Congreso Latinoamericano de Botánica, No. 6 (Fortunato, R.; Bacigalupo, N.; editores). Monographs in Systematic Botany from the Missouri Botanical Garden: 149-172. Mar del Plata.

Troncoso, A.; Suárez, M.; De la Cruz, R.; Palma-Heldt, S. 2002. Paleoflora de la Formación Ligorio Márquez (XI Región, Chile) en su localidad tipo: sistemática, edad e implicancias paleoclimáticas. Revista Geológica de Chile 29 (1): 113-135.

Volkheimer, W.; Novara, M.G.; Narváez, P.L.; Marquillas, R.A. 2006. Palynology and paleoenvironmental significance of the Tunal Formation (Danian) at its type locality, quebrada El Chorro (Salta, Argentina). Ameghiniana 43: 567-584.

Volkheimer, W.; Scafati, L.; Melendi, D.L. 2007. Palynology of a Danian warm climatic wetland in Central Northern Patagonia, Argentina. Revista Española de Micropaleontología 39 (1-2): 117-134.

Whitaker, M.F.; Giles, M.R.; Cannon, S.J.C. 1992. Palynological review of the Brent Group, UK sector, north sea. In Geology of the Brent Group (Morton, A.C.; Haszeldine, R.S.; Giles, M.R.; Brown, S.; editores). The Geological Society, London, Special Publication 61: 169-202. 
Wilf, P.; Singer, B.S.; Zamaloa, M.C.; Johnson, K.R.; Cúneo, N.R. 2010. Early Eocene ${ }^{40} \mathrm{Ar} /{ }^{39} \mathrm{Ar}$ age for the Pampa de Jones plant, frog, and insect biota (Huitrera Formation, Neuquén Province, Patagonia, Argentina). Ameghiniana 47 (2): 207-216.

Wing, S.L.; Harrington, G.J.; Smith, F.A.; Bloch; J.I.; Boyer, D.M.; Freeman, K.H. 2005. Transient floral change and rapid global warming at the PaleoceneEocene boundary. Science 310: 993-996.

Wrenn, J.H.; Kokinos, J.P. 1986. Preliminary comments on Miocene through Pleistocene dinoflagellate cysts from De Soto Canyon, Gulf of Mexico. American As- sociation of Stratigraphic Palynologists, Contribution Series 17: 169-225.

Zachos, J.; Pagani, M.; Sloan, L.; Thomas, E.; Billups, K. 2001. Trends, rhythms, and aberrations in global climate 65 Ma to present. Science 292: 686-693.

Zar, J.H. 1999. Biostatistical Analysis. Prentice Hall, Englewood Cliffs: 663 p. New Jersey.

Zavala, C.; Arcuri, M.; Blanco-Valiente, L. 2012. The importance of plant remains as diagnostic criteria for the recognition of ancient hyperpycnites. Revue de Paléobiologie, Genóve, special volume 11: 457-469.

Manuscript received: September 13, 2012; revised/accepted: November 06, 2012; available online: February 07, 2013. 